\title{
High-resolution structure of a type IV pilin from the metal-reducing bacterium Shewanella oneidensis
}

Manuela Gorgel', Jakob Jensen Ulstrup ${ }^{1}$, Andreas Bøggild ${ }^{1}$, Nykola C Jones ${ }^{2}$, Søren V Hoffmann², Poul Nissen ${ }^{1}$ and Thomas Boesen ${ }^{1 *}$

\begin{abstract}
Background: Type IV pili are widely expressed among Gram-negative bacteria, where they are involved in biofilm formation, serve in the transfer of DNA, motility and in the bacterial attachment to various surfaces. Type IV pili in Shewanella oneidensis are also supposed to play an important role in extracellular electron transfer by the attachment to sediments containing electron acceptors and potentially forming conductive nanowires.

Results: The potential nanowire type IV pilin Pil $\mathrm{Bac}_{\mathrm{Bc}}$ from S. oneidensis was characterized by a combination of complementary structural methods and the atomic structure was determined at a resolution of $1.67 \AA$ by $X$-ray crystallography. Pil Bac1 $_{1}$ consists of one long $N$-terminal a-helix packed against four antiparallel $\beta$-strands, thus revealing the core fold of type IV pilins. In the crystal, Pil Bac $_{\text {f }}$ forms a parallel dimer with a sodium ion bound to

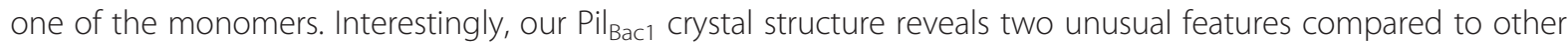
type IVa pilins: an unusual position of the disulfide bridge and a straight a-helical section, which usually exhibits a pronounced kink. This straight helix leads to a distinct packing in a filament model of Pil $\mathrm{Bac}_{1}$ based on an EM model of a Neisseria pilus.
\end{abstract}

Conclusions: In this study we have described the first structure of a pilin from Shewanella oneidensis. The structure possesses features of the common type IV pilin core, but also exhibits significant variations in the a-helical part and the D-region.

Keywords: Type IV pili, Nanowire, PilBac1, PilA, Shewanella oneidensis, X-Ray Crystallography, SAXS, SRCD

\section{Background}

Type IV pili are found in many Gram-negative bacteria as well as in some Gram-positive bacteria and archaea, where they function in numerous cellular processes including adhesion, DNA transfer and virulence [1-6].

Furthermore, in the metal reducing bacteria Shewanella oneidensis and Geobacter sulfurreducens type IV pili have been implicated in extracellular electron transport (EET) pathways [7-9]. Both of these organisms can respire on a variety of electron acceptors, including metals such as iron, manganese and uranium oxides, which has made these organisms attractive research targets in the fields of

\footnotetext{
*Correspondence: thb@mbg.au.dk

'Department of Molecular Biology and Genetics, Aarhus University, Gustav Wieds Vej 10c, Aarhus C 8000, Denmark

Full list of author information is available at the end of the article
}

environmental sciences and nanotechnology [10-15]. S. oneidensis and G. sulfurreducens can reduce extracellular electron acceptors directly through membrane bound cytochromes [16-19]; S. oneidensis can also produce soluble electron shuttles to transfer electrons to extracellular acceptors [20-22]. To allow for highly efficient electron transfer rates, S. oneidensis and G. sulfurreducens can form biofilms in which strong cell-cell interactions and contact between cells and insoluble electron acceptors are beneficial in certain habitats [23-25]. Such an attachment function is expected to implicate type IV pili.

Type IV pili have been associated with a more direct role in EET. Both S. oneidensis and G. sulfurreducens can form conductive filaments that transfer electrons extracellularly over multiple cell lengths from one cell to another and from a cell to an electron acceptor [7,9]. 
These filaments were collectively termed nanowires. While it was clearly shown that nanowires in G. sulfurreducens were made of the type IV pilin PilA, the exact subunits of nanowires in Shewanella have not been identified so far. Yet, there has been strong evidence that nanowires are made of proteins and studies have indicated the contribution of pili in extracellular electron transport $[9,26]$ - whether this is due to an indirect role by attaching to electron acceptors or due to a direct role by nanowire formation, is not clear at this point. Altogether, the high overall similarity between G. sulfurreducens and S. oneidensis, including metabolic pathways, the prevalence of multiheme cytochromes and the formation of conductive filaments, makes it very likely that nanowires in both species are formed in a similar way and function based on the same principles.

Currently, two major hypotheses prevail on how nanowires transfer electrons. The metallic-like conductivity theory claims that type IV pili are the conductive units themselves [27]. The aromatic amino acids in PilA are supposedly aligned so closely that the $\pi$-electrons can be delocalized and be transferred along the pilus like in a metal lattice. According to the alternative multi-step hopping theory, type IV pili only form the backbone of nanowires to which multiheme cytochromes such as $\mathrm{MtrC}$ and OmcA in S. oneidensis and OmcS and OmcZ in G. sulfurreducens, respectively, attach $[28,29]$. The electrons can then hop from one heme of one protein to another heme of the neighboring protein. So far, the electron transfer mechanism along bacterial nanowires is not clear yet and the discussion, on which of the two mechanisms is true, is ongoing [27,28,30,31].

Type IV pilins (T4Ps) build up the polymeric pilus in a repetitive way [32-34]. Two kinds of type IV pilins have been described, type IVa and IVb pilins (T4aPs and T4bPs, respectively). These two types are primarily distinguished by the length of their leader sequences with T4aPs containing an N-terminal leader sequence of 6 to 7 residues, whereas the leader sequences in T4bPs range from 15 to 30 [3]. Generally, T4aPs are synthesized as pre-pilins in the cytoplasm and are guided to the inner membrane by their N-terminal leader sequence [35], which is then cleaved off at a conserved cleavage site by the leader peptidase PilD at the cytoplasmic face of the inner membrane [36,37]. The new N-terminus (commonly a phenylalanine) is then methylated and the processed pilins are inserted into the pilus by an inner membrane multimeric complex (including the assembly ATPase PilB) [38-40] and the assembled pilus is fully exported into the extracellular space via the outer membrane secretin PilQ [41,42]. The $\mathrm{N}$-terminal transmembrane domain of type IV pilins is an approximately 20 residues long hydrophobic $\alpha$-helix, which has a highly conserved sequence among different species. Downstream of this sequence motif, the sequence variability of $\mathrm{T} 4 \mathrm{aPs}$ is however very high and the total length of pilin proteins can vary from 90 residues (G. sulfurreducens) [43] to more than 150 residues (P. aeruginosa) [44].

T4aPs share the signature of the N-terminal leader sequence and the transmembrane $\alpha$-helix with pseudopilins [45] Like a type IV pilus, a pseudopilus extends from the inner membrane into the periplasm, but it does not go beyond the outer membrane [46] (reviewed in [47,48]). Instead, it is associated with the type II secretion system and is involved in the secretion of virulence factors from the periplasm to the extracellular environment [49].

So far, more than 10 structures of different T4Ps and more than 9 structures of pseudopilins have been deposited in the protein data bank (Additional file 1: Table S1). However, only four structures of a full-length T4P are available. All other T4P structures - and all pseudopilin structures - are of N-terminally truncated constructs that do not include the $\mathrm{N}$-terminal hydrophobic transmembrane $\alpha$-helix. This is unfortunate, as this part is the most conserved part among T4Ps and pseudopilins. Still, all structures of T4aPs and pseudopilins exhibit a conserved central core of a long $\mathrm{N}$-terminal $\alpha$-helix packed against three to four antiparallel $\beta$-strands [32,50-52]. However, various structural elements can be inserted around this conserved core allowing for the diverse functions of T4Ps. In 2013 the structure of the nanowire associated pilin PilA from G. sulfurreducens was determined by NMR spectroscopy revealing a single, 61 residue long $\alpha$-helix [43], but as yet, no structure of a T4P from S. oneidensis is available.

In this work, we have determined the structure of the putative nanowire associated T4P on the gene locus SO_0854 [Uniprot: q8eii5] from S. oneidensis by X-Ray crystallography to a resolution of $1.67 \AA$. This T4P from $S$. oneidensis shares the highest degree of sequence identity to PilA from G. sulfurreducens (48\%) when comparing the first 61 residues after the cleavage site (which corresponds to the full length of PilA from G. sulfurreducens). (Additional file 2: Table S2, Additional file 3: Figure S1). The structure reveals the conserved fold of a type IV pilin with a parallel dimer in the asymmetric unit. We have also used Small Angle X-Ray Scattering (SAXS) and Synchrotron Radiation Circular Dichroism (SRCD) to characterize the structure and stability of this protein in solution.

\section{Results and discussion}

\section{Sequence conservation and position in the genome}

The pilin protein encoded by the gene locus SO_0854 exhibits the conserved $\mathrm{N}$-terminal leader sequence (MNTLQKG) and a hydrophobic patch of 22 residues expected to form a transmembrane helix, which is the hallmark of both type IV pilins and pseudopilins [45] (Figure 1A). Additionally, it possesses two conserved 


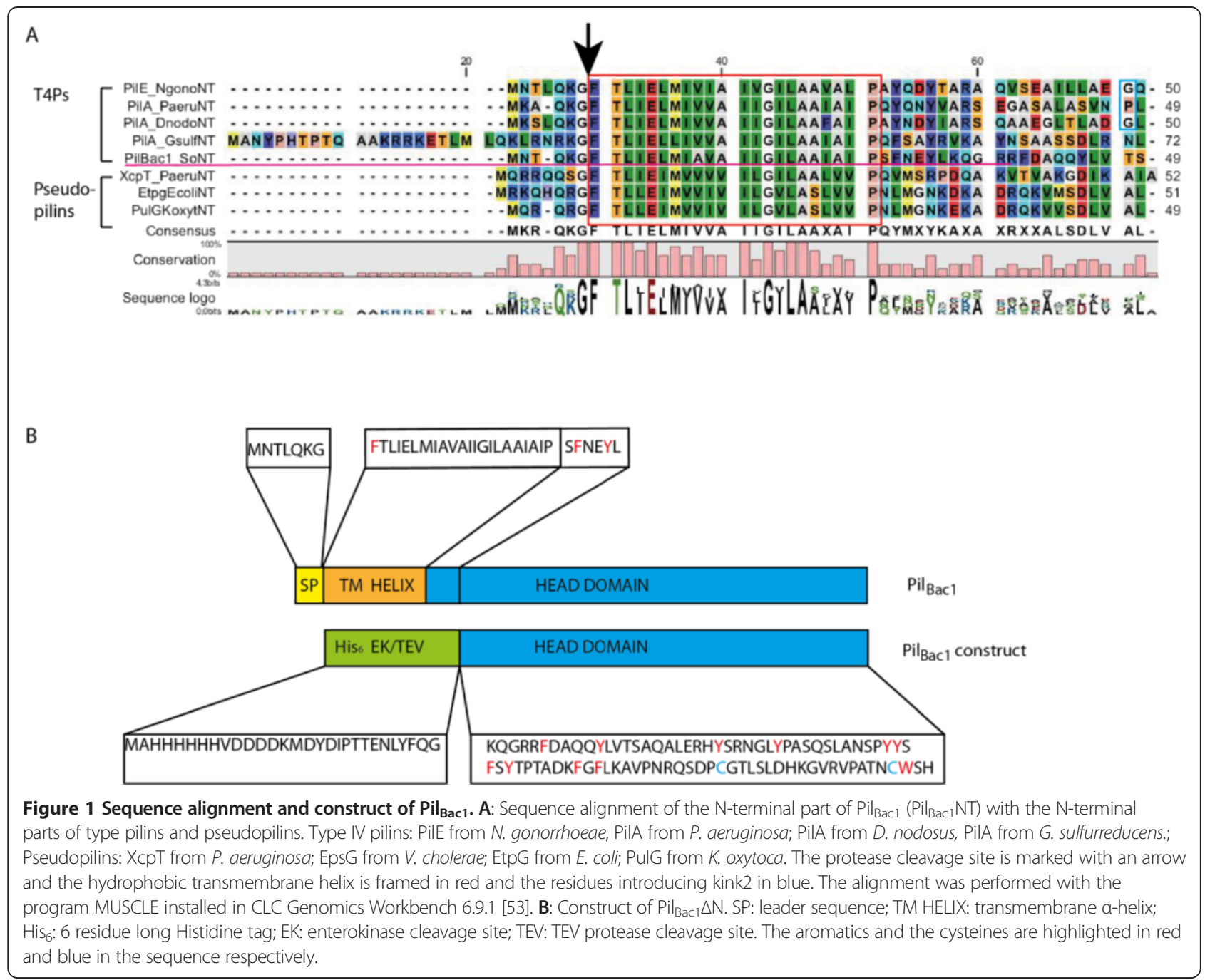

cysteines in the C-terminal part (Cys96, Cys113) which form a disulfide bridge in T4Ps. Based on these features, we classified the protein SO_0854 as a type IV pilin and added it to the subclass of T4aPs due to its short leader sequence.

So far, no consistent nomenclature for T4Ps has been established and therefore, newly described T4Ps cannot be named unambiguously. The low sequence similarity among T4Ps further complicates the naming process. For this reason, the naming of the T4P on the gene locus SO_0854 will briefly be outlined here. SO_0854 is the first open reading frame in a gene cluster consisting of three other putative type IV pilins (SO_0853, SO_0852, SO_0851) and a type IV pilin adhesin with a bactofilin motif (SO_0850). Bactofilins are fiber forming, membrane attached proteins that have been identified in many Gram-negative bacteria and they are associated with cytoskeleton related functions such as cell motility, cell morphology and cell division [54,55]. In M. xanthus the polymerized bactofilin BacP directly interacts with PilB and PilT which are responsible for extension and retraction of type IV pili, respectively, and thus for the motility of the cell [56]. In $S$. oneidensis a bactofilin (SO_1662) [53] was shown to localize to the cell division ring and this bactofilin was therefore assumed to be associated with cell division [54]. Even though bactofilins constitute a recently discovered protein family and their functions have not been fully elucidated yet, the finding of this motif in the putative adhesin in this operon is intriguing. For this reason, we named the five pilin proteins on the gene loci SO_0854, SO_0853, SO_0852, SO_0851 and $\mathrm{SO}$ 0850 $\mathrm{Pil}_{\mathrm{Bac} 1}, \mathrm{Pil}_{\mathrm{Bac} 2}, \mathrm{Pil}_{\mathrm{Bac} 3}, \mathrm{Pil}_{\mathrm{Bac} 4}$ and $\mathrm{Pil}_{\mathrm{Bac} 5}$ respectively.

\section{Construction and purification of a soluble construct}

To obtain a soluble version of $\mathrm{Pil}_{\mathrm{Bac} 1}$, a construct was designed that lacks the $\mathrm{N}$-terminal 35 residues including the signal peptide and the transmembrane $\alpha$-helix. Instead, a His-tag and a TEV protease cleavage site were inserted to enable tag removal (leaving one N-terminal glycine) during the purification process (Figure 1B). This 
construct was termed $\operatorname{Pil}_{\mathrm{Bac1}} \Delta \mathrm{N}$. The protein was wellexpressed in E. coli and could be purified to homogeneity in a two-step purification procedure using two passes over a Ni-column (before and after tag removal) followed by size exclusion chromatography. Size exclusion chromatography of $\mathrm{Pil}_{\mathrm{Bac}} \Delta \mathrm{N}$ gave a monodisperse peak and, comparing the elution volume with those of globular standard proteins that were used for calibration of the size exclusion column, a molecular weight of $11 \mathrm{kDa}$ was estimated, which is close to the theoretical monomeric weight of $9.9 \mathrm{kDa}$.

\section{Thermostability of $\mathrm{Pil}_{\mathrm{Bac} 1} \Delta \mathrm{N}$}

The stability of $\mathrm{Pil}_{\mathrm{Bac} 1} \Delta \mathrm{N}$ was assessed by SRCD measurements where the temperature was increased stepwise from 7 to $81^{\circ} \mathrm{C}$ and data were recorded from $280 \mathrm{~nm}$ to $190 \mathrm{~nm}$ (Figure 2). With increasing temperature the signal strength at 195, 210 and $222 \mathrm{~nm}$ fell, indicating a change or a loss of structure. Interestingly, this effect was partly reversed when re-cooling the sample back to $24^{\circ} \mathrm{C}$ indicating that the protein could, at least partially, refold. The change of the structure was analyzed with principle component analysis (PCA) (Figure 2B) and the contribution of the different components relative to the temperature is shown in Figure 2C. The inflection points of both curves yield an approximate melting temperature of 36 and $38^{\circ} \mathrm{C}$ respectively. A somewhat higher value $\left(42^{\circ} \mathrm{C}\right)$ was obtained in a Thermofluor assay (data not shown). In the Thermofluor experiment, a steeper gradient was applied and this might have resulted in a higher melting temperature compared to the SRCD measurements. In general, a melting temperature around or below $40^{\circ} \mathrm{C}$ has been claimed to counteract crystallization [57].

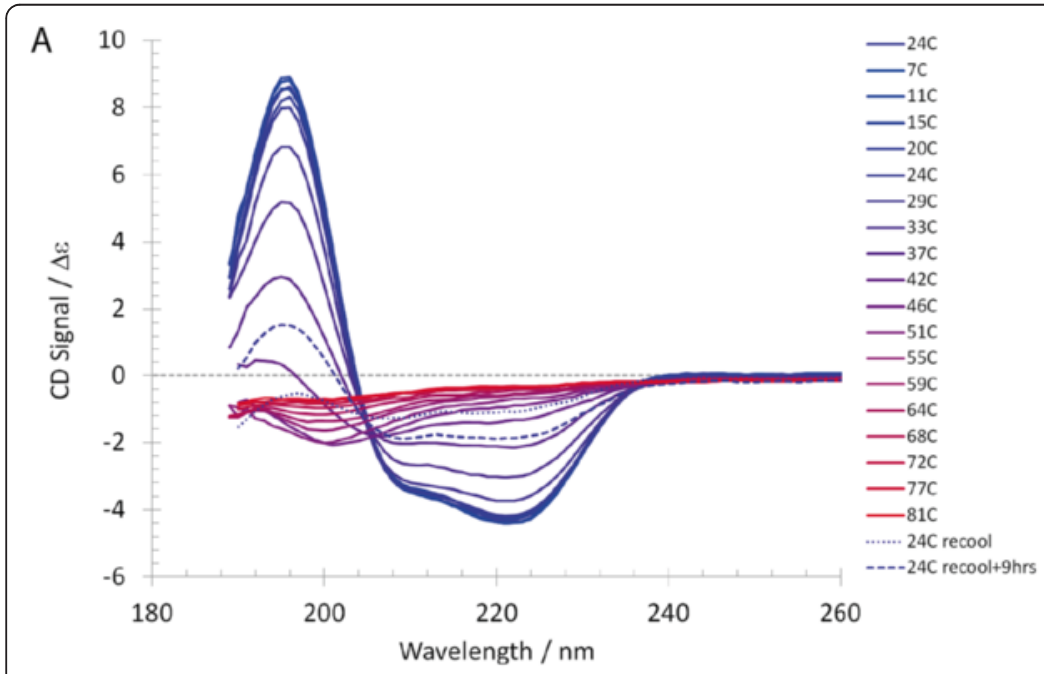

B
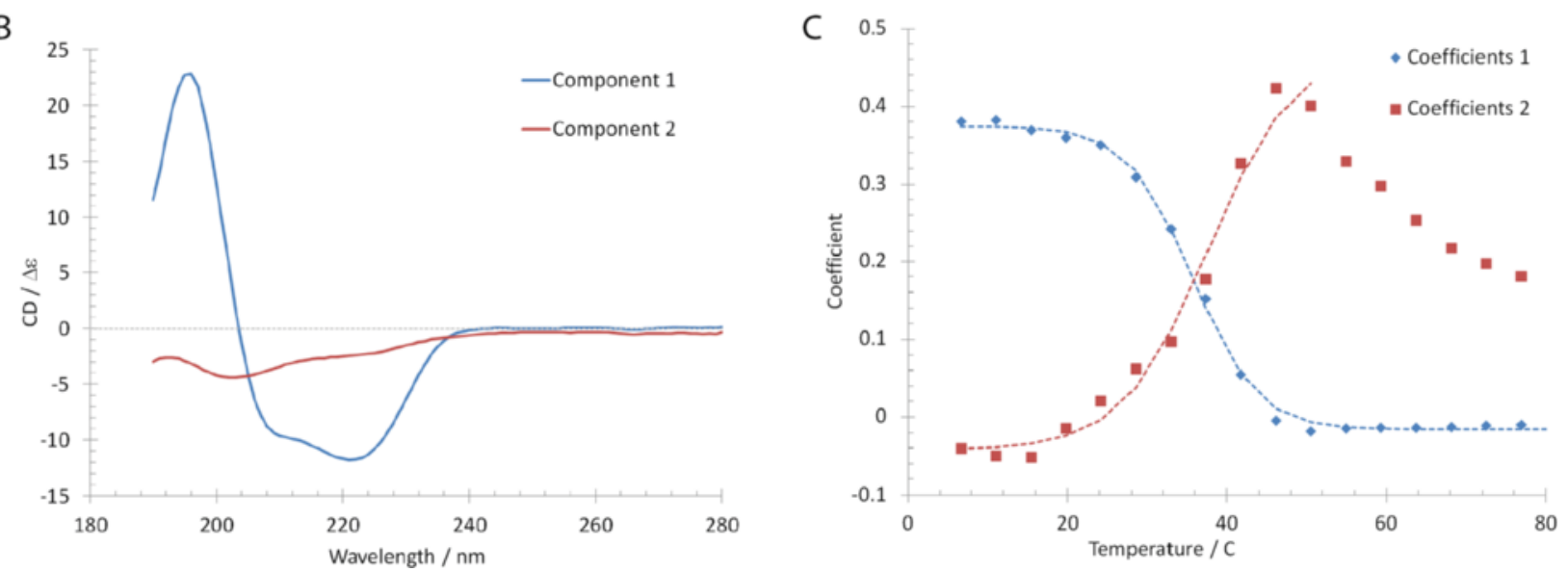

Figure 2 Temperature scan of $\mathrm{Pil}_{\mathrm{Bac} 1} \Delta \mathbf{N}$ using SRCD. A: SRCD spectra with increasing temperature shown with data from 260 to $190 \mathrm{~nm}$. B: Plot of the component curves resulting from principal component analysis of the CD data set in A, with the associated coefficients plotted in C. C: A fit of the coefficients for component 1 (blue) with a sigmoidal function to find the inflection point yields a melting temperature of $36^{\circ} \mathrm{C}$, while fitting up to $50^{\circ} \mathrm{C}$ for component 2 yields a value of $38^{\circ} \mathrm{C}$ 


\section{X-ray crystallography}

An initial hit was obtained in the Structure Screen from Molecular Dimensions in condition $42\left(0.2 \mathrm{M}\left(\mathrm{NH}_{4}\right)\right.$ ${ }_{2} \mathrm{SO}_{4}, 30 \%$ PEG 8,000$)$ at $15 \mathrm{mg} / \mathrm{ml}$ at $19^{\circ} \mathrm{C}$. These crystals could not be reproduced when manually recreating the conditions. Introducing $100 \mathrm{mM}$ CHES pH 8.6 as a buffer component into the crystallization condition yielded crystals of around 50x50x500 $\mu^{3}$. Additionally, the ratio between protein and reservoir solution was increased from 1:1 to 2:1. The best looking crystals were consistently obtained at 26\% PEG 8,000, $0.15 \mathrm{M}\left(\mathrm{NH}_{4}\right)$ ${ }_{2} \mathrm{SO}_{4}$ and $0.1 \mathrm{M}$ CHES pH 8.6. The crystal structure of $\mathrm{Pil}_{\text {Bac1 }} \Delta \mathrm{N}$ was initially determined by sulfur SAD at $2 \AA$ resolution based on the anomalous signal of the two cysteines in the C-terminal domain, a bound sulfate molecule and a bound sodium ion (structure determination described in another manuscript). A high resolution data set was collected on another crystal and data were processed in the high symmetry space group I222 to a resolution of $1.67 \AA$ using the $C_{1 / 2}$ value as a cut-off [58] (Table 1). The model obtained from S-SAD was then used as a search model in molecular replacement for this data set, and all residues were modelled into clear electron density with no apparent ambiguities. The crystal form had a large solvent content (62\%) yielding a high optical resolution and favorable data-to-parameter ratio at $1.67 \AA$ resolution. Riding hydrogen atoms were included in the last model refinement and this resulted in a decrease in $\mathrm{R}_{\text {free }}$ of $1 \%$.

Additional density was observed at the interface to the large solvent channels of the crystal. This density could not be attributed to solvent or an additional copy of the protein, but probably integrates features of partially associated molecules from the mother liquor or buffer solutions used for purification, such as PEG, glycerol, ions and water (Additional file 4: Figure S2).

\section{Overall structure}

$\mathrm{Pil}_{\mathrm{Bac} 1} \Delta \mathrm{N}$ consists of one long $\mathrm{N}$-terminal $\alpha$-helix packed against 4 antiparallel $\beta$-strands resembling the core fold of type IV pilins (Figure 3A). A long loop forms the $\alpha \beta$-loop connecting the $\alpha$-helix and the first $\beta$-strand. This region is among the most variable parts in T4P structures and can contain insertions of a short $\alpha$-helix or a short $\beta$-strand or simply display a random coil loop structure as it is the case for $\operatorname{Pil}_{\text {Bac1 }} \Delta \mathrm{N}$. The two cysteines in the loops b2-b3 and the loop after b4 indeed form the conserved disulfide bridge of T4Ps that forms the disulfide-bounded loop region (D-region) and keeps strands 3 and 4 together.

$\mathrm{Pil}_{\text {Bac1 }} \Delta \mathrm{N}$ exhibits two positively charged surface patches at the $\mathrm{N}$ - and at the $\mathrm{C}$-terminus of the $\alpha$-helix due to closely spaced arginines and lysines facing the solvent area (Figure $3 \mathrm{~B}$ and $\mathrm{C}$ ). A negatively charged patch is formed by residues in the $\mathrm{C}$-terminus and the top of the head domain. These charged regions might act as a platform for interactions with other molecules, for example with other pilins in the pilus or receptors for attachment. For instance, in the structure of PilE from Neisseria gonorrhoeae docked into an EM envelope of a pilus, positively charged patches were suggested to be responsible for DNA binding [34]. For a pilin protein from $S$. oneidensis such as $\mathrm{Pil}_{\mathrm{Bac1}}$, potential binding partners could be multiheme cytochromes which were suggested to be the electron transporting components in nanowires [28,29]. In G. sulfurreducens, the multiheme cytochrome OmcS was shown to co-localize with nanowires suggesting a direct interaction [63] and a similar interaction can be expected from multiheme cytochromes in S. oneidensis.

\section{Comparison to other type IV pilins and pseudopilins}

$\mathrm{Pil}_{\text {Bac1 }} \Delta \mathrm{N}$ is structurally similar to other T4Ps in the $\alpha$-helix and the first two $\beta$-strands. However, variable regions are also characteristic of type IV pilins. These include the $\alpha \beta$-loop and the loops connecting the $\beta$-strands and parts of the D-region. The loops between the $\beta$-strands have been proposed to be involved in contact formation with interaction partners [34]. In $\mathrm{Pil}_{\mathrm{Bac} 1} \Delta \mathrm{N}$, loops b1-b2 and b2-b3 are relatively long. Compared to other type IV pilins, $\operatorname{Pil}_{\mathrm{Bac} 1} \Delta \mathrm{N}$ is very compact without any additional motifs or insertions, mostly due to its short sequence relative to other T4P head domains. In the reported structures of T4aPs, a disulfide bridge is usually formed between cysteines in the fourth $\beta$-strand (b4) and the last loop (Additional file 1: Table S1). In contrast, in $\mathrm{Pil}_{\mathrm{Bac} 1}$ the first cysteine is not situated in b4, but in the loop from b2 to b3. Another exception is the structure of PilA_4 in which the disulfide bridge is formed by two cysteines in $\beta$-strands b3 and b4 [64].

In general, structures of full-length T4Ps exhibit two kinks in the long N-terminal $\alpha$-helix, one in the transmembrane part (kink 1) and one in the C-terminal part of the $\alpha$-helix (kink 2) (Additional file 1: Table S1). These two kinks are due to helix breaking residues (prolines or glycines) at positions 22 and 42, which are conserved among most T4aPs. Interestingly, $\mathrm{Pil}_{\mathrm{Bac} 1}$ possesses a helix breaking proline at position 22 , but a helix breaking residue is missing at position 42 (Figure 1). Therefore, kink 2 is missing in $\mathrm{Pil}_{\mathrm{Bac} 1}$ and the $\alpha$-helix in the structure of $\mathrm{Pil}_{\text {Bac1 }} \Delta \mathrm{N}$ is straight. Such a feature has commonly been observed in structures of pseudopilins and in the T4bPs PilS from S. typhi and TcpA from V. cholerae as well as in two T4a pilins, namely PilA from G. sulfurreducens and PilA_4 from T. thermophilus. The feature of a straight $\alpha$-helix could suggest a different mode of packing in the pilus (see below). 
Table 1 Data collection and processing statistics for the structure of $\mathrm{Pil}_{\mathrm{Bac} 1} \Delta \mathrm{N}$

\begin{tabular}{|c|c|}
\hline Subset & Native \\
\hline Crystallization condition & $26 \%$ PEG 8,000, 0.1 M CHES pH 8.6, $0.15 \mathrm{M}\left(\mathrm{NH}_{4}\right)_{2} \mathrm{SO}_{4}$ \\
\hline Beamline & BL-14.2, BESSY-II, Helmholtz Zentrum Berlin, DE \\
\hline Detector & Rayonix MX225 \\
\hline Wavelength $(\AA)$ & 0.918409 \\
\hline Crystal to Detector Distance (mm) & 150.0 \\
\hline Rotation/ Frame $\left(^{\circ}\right)$ & 0.5 \\
\hline Number of Frames & 200 \\
\hline \multicolumn{2}{|l|}{ Data Processing statistics } \\
\hline Resolution ( $\AA$ ) & $48.23-1.67(1.70-1.67)$ \\
\hline Space group & 1222 \\
\hline Unit cell parameters $\left(\AA{ }^{\circ}\right)$ & $48.91,96.46,110.33 ; 90.0,90.0,90.0$ \\
\hline No. of unique reflections & $56,946(4,148)$ \\
\hline No. of total reflections & $111,644(8,093)$ \\
\hline Multiplicity & $1.96(1.95)$ \\
\hline Completeness (\%) & $97.0(95.1)$ \\
\hline$R_{\text {merge }}^{\mathrm{a}}$ & $0.039(0.641)$ \\
\hline$R_{\text {r.i.m. }}^{\mathrm{b}}$ & $0.054(0.890)$ \\
\hline Wilson B-factor $\left(\AA^{2}\right)$ & 23.12 \\
\hline Mean $\mid / \sigma l$ & $13.3(1.2)$ \\
\hline $\mathrm{CC}_{1 / 2}$ & $0.999(0.578)$ \\
\hline \multicolumn{2}{|l|}{ Refinement statistics } \\
\hline$R_{\text {work }}$ & 0.1798 \\
\hline$R_{\text {free }}$ & 0.2075 \\
\hline Number of non-hydrogen atoms modelled & 1631 \\
\hline Number of non-hydrogen protein atoms & 1406 \\
\hline Number of ligand atoms & 6 \\
\hline Number of solvent molecules & 219 \\
\hline \multicolumn{2}{|l|}{ R.M.S.D. from ideal values } \\
\hline Bonds $(\AA)$ & 0.004 \\
\hline Angles $\left({ }^{\circ}\right)$ & 1.101 \\
\hline \multicolumn{2}{|l|}{ Ramachandran } \\
\hline Favoured (\%) & 99 \\
\hline Outliers (\%) & 0 \\
\hline Clash Score & 0.73 \\
\hline Average B-factor $\left(\AA^{2}\right)$ & 34.6 \\
\hline Average B-factor for protein $\left(\AA^{2}\right)$ & 33.7 \\
\hline Average B-factor for ligands $\left(\AA^{2}\right)$ & 61.4 \\
\hline Average B-factor for solvent molecules $\left(\AA^{2}\right)$ & 39.7 \\
\hline
\end{tabular}

Data were processed with XDS [59]. The structure was determined and built and refined with Phenix and COOT [60,61]. Values in parentheses are given for the

${ }^{\mathrm{a}}: R_{\text {merge }}=\sum_{h k l} \sum_{i}|l i(h k l)-l(\bar{h} k l)| \sum_{h k l} \sum_{i} l i(h k l)[62] ;{ }^{\text {b }}: R_{\text {r.i.m. }}=\sum_{h k l}[N /(N-1)]^{\frac{1}{1}} \sum_{i}|l i(h k l)-l(\overline{h k l})| \sum_{h k l} \sum_{i} l i(h k l)[62]$.

To identify homologous structures to $\operatorname{Pil}_{\mathrm{Bac} 1} \Delta \mathrm{N}$, a search with the DALI server [65] was performed (Additional file 5: Table S3). As expected, structures of type IV pilins scored the highest and among them, the highest score was seen with the T4aPs PilA_4 from T. thermophilus [64] (4BHR.PDB; DALI: Score: 8.7), followed by the minor pilin PilX from N. meningitis [66] (2OPD.PDB; DALI: Score: 8.3 ) and the PAK pilin from $P$. aeruginosa 


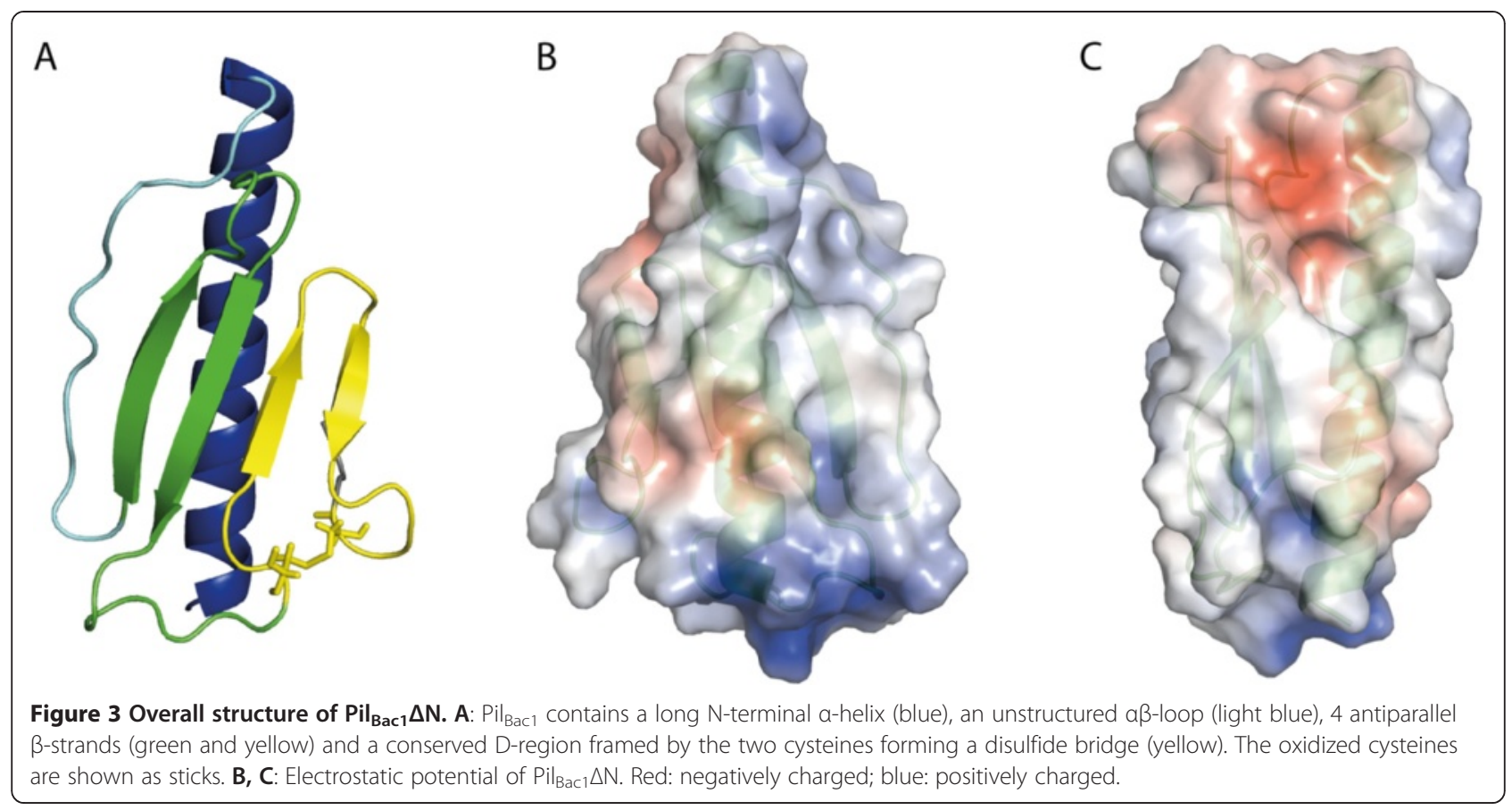

[67] (1X6Z.PDB; DALI: Score: 8.1) (Figure 4A-C). PilA_4 is one of the exceptions of T4aPs with a straight, continuous $\alpha$-helix and superimposes well with $\operatorname{Pil}_{\mathrm{Bac}} \Delta \mathrm{N}$ (Figure 4A). The biggest variation between PilA_4 and $\mathrm{Pil}_{\mathrm{Bac} 1} \Delta \mathrm{N}$ lies in the $\alpha \beta$-loop, which forms a short $\alpha$-helix in PilA_4 and a random coil structure in $\operatorname{Pil}_{\mathrm{Bac1}} \Delta \mathrm{N}$.

$\mathrm{Pil}_{\text {Bac1 }} \Delta \mathrm{N}$ also shares structural similarity with pseudopilins, which superimpose well in the core regions (Figure 4D). As for other type IV pilins, the biggest differences are observed in the variable regions. Additionally, pseudopilins coordinate a calcium ion in the D-region, where $\mathrm{Pil}_{\mathrm{Bac1}} \Delta \mathrm{N}$ and other type IV pilins form a conserved disulfide bridge [68].

$\mathrm{Pil}_{\mathrm{Bac1}} \Delta \mathrm{N}$ overlays well with the $\alpha$-helix of PilA from G. sulfurreducens and the feature of a straight $\alpha$-helix after the transmembrane part (Figure 4E); yet, this T4aP structure was not scored high by the DALI server, as PilA from G. sulfurreducens does not contain a head domain. Noteworthy, a gene (GSU1497) is located directly downstream of pilA that codes for a protein that was shown to be up-regulated together with PilA and a few multiheme cytochromes in microbial fuel cells [69]. Furthermore, PilA was not detected by western blotting in strains deficient for GSU1497 [70]. Therefore, this protein might constitute the missing head domain of PilA from G. sulfurreducens and a future structural comparison of this protein with $\mathrm{Pil}_{\mathrm{Bac}} \Delta \mathrm{N}$ would be very interesting.

\section{Dimeric interface}

$\mathrm{Pil}_{\mathrm{Bac1}} \Delta \mathrm{N}$ was crystallized as a parallel dimer in the asymmetric unit in which the interface is formed by interactions between 15 and 20 residues in the $\alpha$-helix from monomers $\mathrm{A}$ and $\mathrm{B}$, respectively (forming a nonproper dimer with a screw-axis) (R.M.S.D. of $0.309 \AA$ based on 79 out of a total of $89 \mathrm{C}_{\alpha} \mathrm{s}$ )(Figure 5A). Previously it was noted that pilins can exist as dimers and multimers [71-73]. Many structures of type IV pilins and pseudopilins were also determined in a dimeric $[32,68,74-78]$ or even in a trimeric state [68]. However, different to $\operatorname{Pil}_{\text {Bac1 }} \Delta \mathrm{N}$, most of them were not arranged in a physiologically relevant conformation (e.g. antiparallel, inline). The structures of the T4P CofA from E. coli (3S0T. PDB) and of the pseudopilin PulG from E. coli (3G20. PDB) were determined as dimers, in which the monomers are further apart from each other. This dimerization was probably caused by crystal contacts. In contrast, in the structure of full-length FimA from $D$. nodosus, the two monomers are held together by extensive, intermolecular interactions. However, unlike $\mathrm{Pil}_{\text {Bac } 1} \Delta \mathrm{N}$, the dimeric interface is here formed between the transmembrane domains.

Since the $\mathrm{N}$-terminal transmembrane domain in $\mathrm{Pil}_{\text {Bac1 }} \Delta \mathrm{N}$ is missing in the structure, we modelled this conserved part based on the full-length structure of mature PilE from $N$. gonorrhoeae, as this region is highly conserved in T4Ps as a transmembrane $\alpha$-helix (Figures 1 and 5A-D; R.M.S.D. of the $\alpha$-helices and the first two $\beta$-strands: $1.7 \AA$ ). This additional domain extends the $\alpha$-helices in both monomers in the crystal dimer by a further 28 residues without the introduction of any clashes (Figure 5E). Consequently, this arrangement maintains contacts between both monomers and allows for the existence of the dimer in a membrane (Figure 5E). 


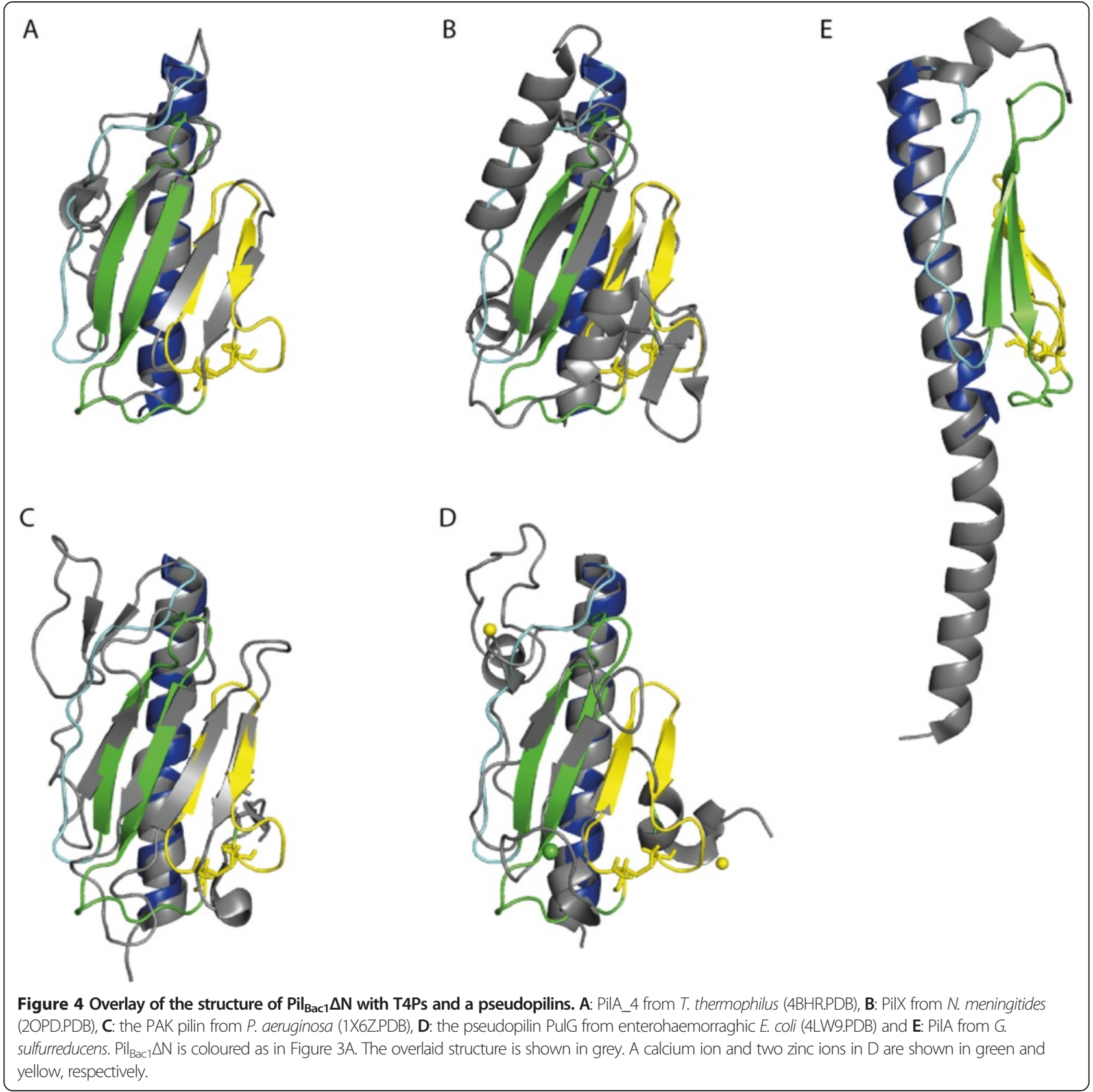

In the modelled part of the alpha helix, a kink is introduced due to the presence of a conserved helix breaking proline in the transmembrane helix at position 22 (kink1). Such a kink has been described in all four available full-length structures of T4Ps $[32,43,77,80]$ and separates the $\mathrm{N}$ - and the C-terminal parts of the helix from each other.

To assess the oligomeric state of $\mathrm{Pil}_{\mathrm{Bacl}} \Delta \mathrm{N}$ in solution we performed SAXS studies at concentrations ranging from $1-16 \mathrm{mg} / \mathrm{ml}$ (Additional files 6: Table S4, Additional file 7: Figure S3). No signs of aggregation or repulsive forces were observed from the scattering data at any of these concentrations as judged by comparison of the scattering intensities at low scattering angles for all concentrations used. Guinier and Porod analysis revealed a radius of gyration of 14 and $16 \AA$ respectively, and the molecular mass determined by Porod volume analysis indicated a molecular weight of only $6 \mathrm{kDa}$, which is below the theoretical molecular mass of $9.9 \mathrm{kDa}$. Kratky analysis indicated a well-folded molecule (Additional file 7: Figure S3). Altogether, these findings indicated that $\mathrm{Pil}_{\mathrm{Bacl}} \Delta \mathrm{N}$ existed as a monomer in solution. A dummy atom (DA) model of $\operatorname{Pil}_{\text {Bac1 }} \Delta \mathrm{N}$ was built by the program DAMMIF based on the SAXS data [81] and the crystal structure of monomeric $\mathrm{Pil}_{\mathrm{Bac1}} \Delta \mathrm{N}$ compared to 


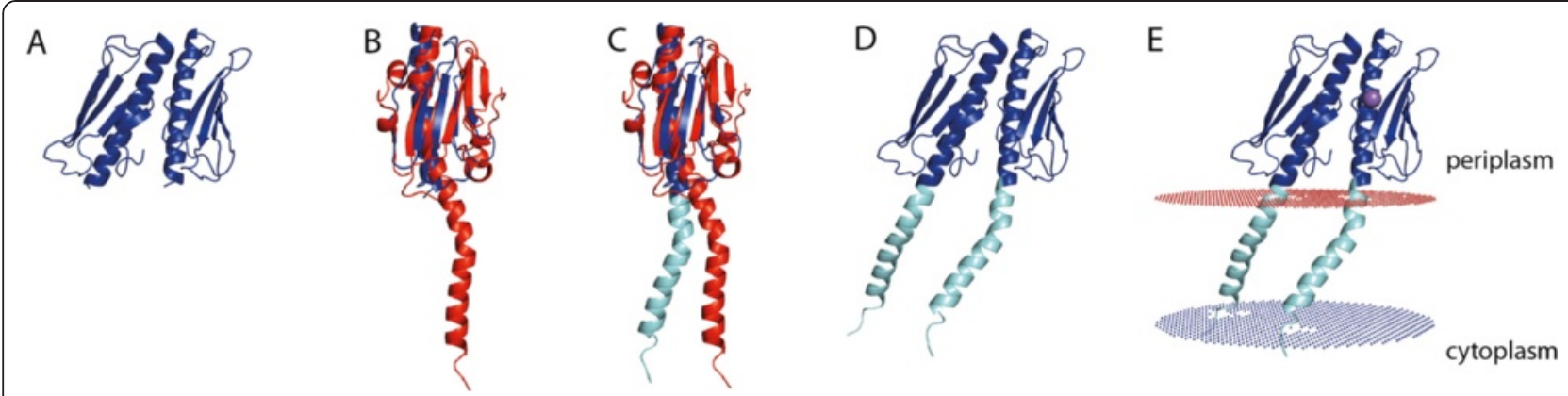

Figure 5 Dimer of $\mathrm{Pil}_{\mathrm{Bac}} \Delta \mathbf{N}$. A: Dimeric interface between two Pil $\left.\right|_{\text {Bac } 1} \Delta \mathrm{N}$ molecules in the crystal. B: Superposition of a Pil $\left.\right|_{\text {Bac } 1} \Delta \mathrm{N}$ monomer with PilE from N. gonorrhoeae (2HI2.PDB). C: Superposition based on the head domains of a Pil Bac $1_{1} \Delta \mathrm{N}$ monomer with the modelled a-helix onto PilE from $N$. gonorrhoeae (2HI2.PDB). D: Pil Bacl $_{1} \Delta \mathrm{N}$ dimer with the modelled a-helices at the $\mathrm{N}$-terminus based on a superposition with the a-helix from

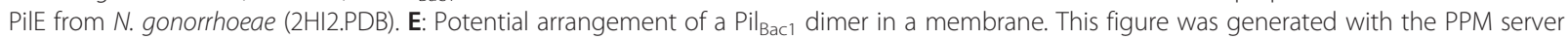
[79]. The structure of $\mathrm{Pil}_{\mathrm{Bac} 1} \Delta \mathrm{N}$ is shown in blue, the modelled helix in cyan and PilE from N. gonorrhoeae is shown in red.

the DA model using the program SUPCOMB [82], yielding a good fit. In UCSF Chimera [83] a simulated map at $10 \AA$ based on the crystal structure was fitted to a SAXS envelope based on the DA model giving a CC of 0.762 (Figure 6). A scattering curve was calculated on the basis of the crystal structure using the program CRYSOL [84] and compared to the experimentally measured scattering data. This resulted in a chi value (discrepancy between the theoretical and experimental scattering curve) of 1.82, which is indicative of good agreement.

The results from the SAXS analysis were further substantiated by size exclusion chromatography and a PISA analysis [86], which indicated that the $\mathrm{Pil}_{\mathrm{Bac1}} \Delta \mathrm{N}$ dimer interface energy was low. However, the environment in a membrane with potentially interacting transmembrane helices is very different from that of a truncated protein in solution, the local concentration of pilins is significantly higher and the degree of translational freedom is reduced in a membrane. Therefore we cannot exclude a possible function of dimeric $\mathrm{Pil}_{\mathrm{Bac} 1}$ in the membrane, but further studies on the full-length $\mathrm{Pil}_{\mathrm{Bac1}}$ in membranes and assembled into pili will be needed to evaluate oligomeric states of $\mathrm{Pil}_{\mathrm{Bac} 1}$.

\section{$\mathrm{Na}^{+}$-lon binding site}

In chain B clear density was observed, both in the anomalous map from the S-SAD data with a peak height of $6.5 \sigma$ (described in another manuscript) and in the $2 \mathrm{mFo}-\mathrm{DFc}$ map from the high resolution data set, for an ion bound between the a $\beta$-loop and the first $\beta$-strand. This ion was octahedrally coordinated by oxygen atoms (carbonyl oxygen of Leu36 and Phe44, delta oxygen of Asn $38,3 \mathrm{H}_{2} \mathrm{O}$ molecules) with average coordination distances of $2.5 \AA$ (Figure 7A). In agreement with these coordination properties, its anomalous scattering intensity

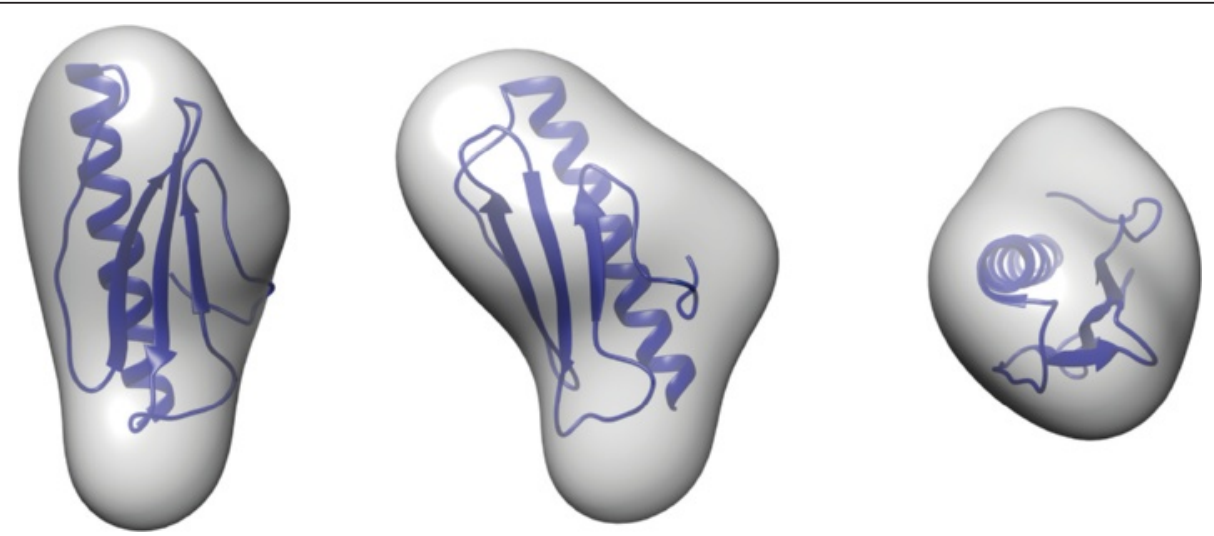

Figure 6 Crystal structure of $\mathrm{Pil}_{\mathrm{Bac} 1} \Delta \mathrm{N}$ docked into its SAXS envelope. A dummy atom model from the SAXS data was generated with DAMMIF [81] and superposed onto the crystal structure with SUPCOMB [82]. This oriented SAXS model was then converted into an envelope with the pdb2vol software from the SITUS package $[81,85]$. 

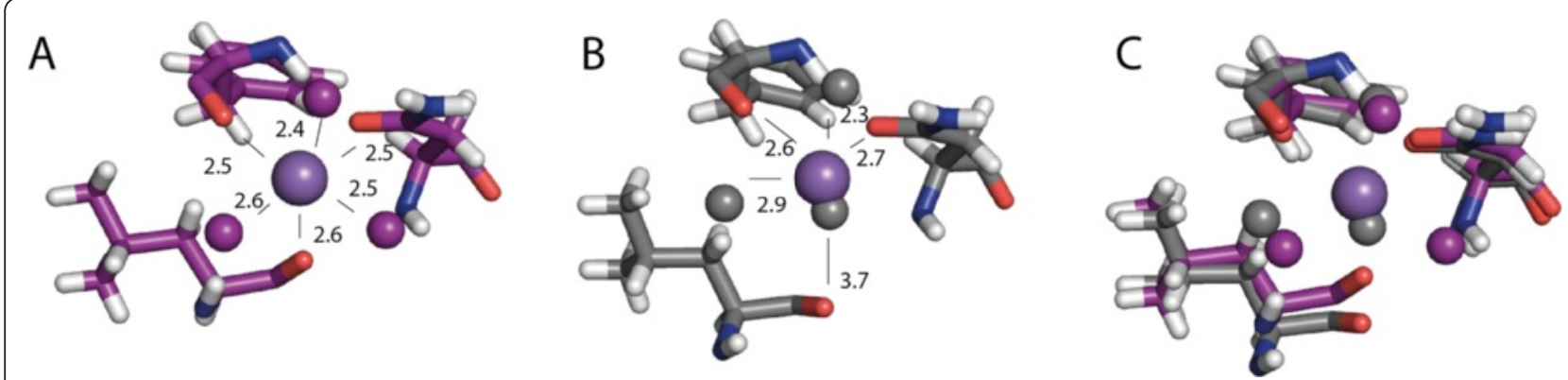

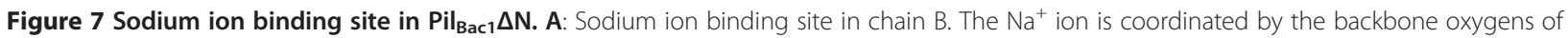
Leu36 and Phe44, as well as the side chain oxygen of Asn38 and three water molecules. B: Homologous ion binding site in chain A with a superposed sodium ion from chain B. C: Superposition of the ion binding site in chain B, with the homologous residues in chain A. The carbonyl oxygen of Leu36 is moved further away from the sodium in chain A with respect to chain B increasing the distance to the $\mathrm{Na}^{+}$ion to $3.7 \AA$. Molecules from chain A are shown in grey, molecules from chain B in purple. Distances in $\AA$ to the position of the sodium ion in chain $B$ are shown in black.

and consistent with the presence of $100 \mathrm{mM} \mathrm{NaCl}$ in the buffer, we assigned this ion to a sodium ion (described in another manuscript).

Interestingly, this sodium ion was not observed in chain A due to a slight distortion of the ion binding site compared to chain B. The backbone of Leu36 is further away from the binding site increasing the distance from 2.6 to $3.7 \AA$ (Figure $7 \mathrm{~B}$ and $\mathrm{C}$ ). Additionally, a third water molecule is missing to coordinate the ion; instead, another water molecule binds in the position where the sodium binds in chain B. Furthermore, features of positive density lie between the sodium ion binding site in chain A and a symmetry related molecule. This density is indicative of a bound molecule such as PEG which might have interfered with binding of the ion in this site.

So far, no functionally validated binding of any ions has been described for T4Ps. For pseudopilins the stabilization by calcium ions has been shown [68]. Whether the bound sodium ion in $\mathrm{Pil}_{\mathrm{Bac} 1} \Delta \mathrm{N}$ fulfills a functional role or is a crystal artefact due to the $100 \mathrm{mM}$ $\mathrm{NaCl}$ in the buffer, is not clear yet. Hypothetically, the $\mathrm{Na}^{+}$ion could act as a regulator in filament assembly. In the extracellular space and periplasm, the sodium concentration is much higher than intracellularly and we find it possible that the pilin might bind a sodium ion in the periplasm.

\section{Modelling of a $\mathrm{Pil}_{\mathrm{Bac} 1}$ pilus}

To investigate the putative packing in a pilus, a model composed of $\mathrm{Pil}_{\mathrm{Bac} 1}$ subunits was generated (Figure 8). In order to do this, an atomic pilus model based on the EM structure of a PilE pilus and the crystal structures of PilE from $N$. gonorrhoeae were used as a template [34]. First, the structure of a $\mathrm{Pil}_{\mathrm{Bac} 1} \Delta \mathrm{N}$ monomer was superimposed onto monomeric PilE and the missing $\mathrm{N}$-terminal 28 residues were modelled resulting in a full-length model of $\mathrm{Pil}_{\mathrm{Bac} 1}$. This full-length chimera was then overlaid onto the individual subunits in the PilE pilus based on the modelled, very similar transmembrane part. No significant clashes between the subunits were introduced, only minor clashes between the $\mathrm{N}$-terminal part of the helix of one monomer and the C-terminal part of the helix of the neighboring monomer (Figure 8B).

As for the Neisseria pilus, the $\alpha$-helices formed the central core with the head domains facing outwards; however, in contrast to the Neisseria pilus, the packing seemed to be less dense due to the missing kink in the C-terminal part of the helix (kink 2) and due to a smaller head domain. The positively charged patch at the $\mathrm{N}$-terminus from one pilin is located closely to the negatively charged patch of the neighbouring pilin stabilizing the interaction between pilins in the pilus filament. (Figure $8 \mathrm{C}$ ). Overall, the $\mathrm{Pil}_{\mathrm{Bac} 1}$ pilus was a bit thinner than for Neisseria, because the head domain in $\mathrm{Pil}_{\mathrm{Bac} 1}$ is less bulky with no major grooves or protrusions on the surface.

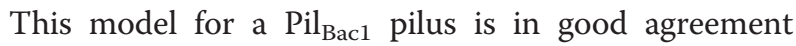
with the general observations that the D-region is involved in the interaction with other molecules [1,87] and should be solvent accessible. Still, it needs to be considered that this model is based on a model pilus from $N$. gonorrhoeae which in turn is based on the docking of the crystal structure of PilE into an EM envelope. Unlike PilE, Pil ${ }_{\text {Bac1 }}$ does not contain a kink in the $\alpha$-helix after the transmembrane part which will orient the head domain in a slightly different angle (kink2). This will necessarily affect the packing pattern in a pilus and inevitably lead to differences to the PilE pilus and therefore, this model has to be interpreted with some caution.

\section{Aromatic amino acids in $\mathrm{Pil}_{\mathrm{Bac} 1}$}

Malvankar and co-workers have proposed that nanowires from G. sulfurreducens are conductive due to the close positioning of aromatic amino acids in PilA [27]. 


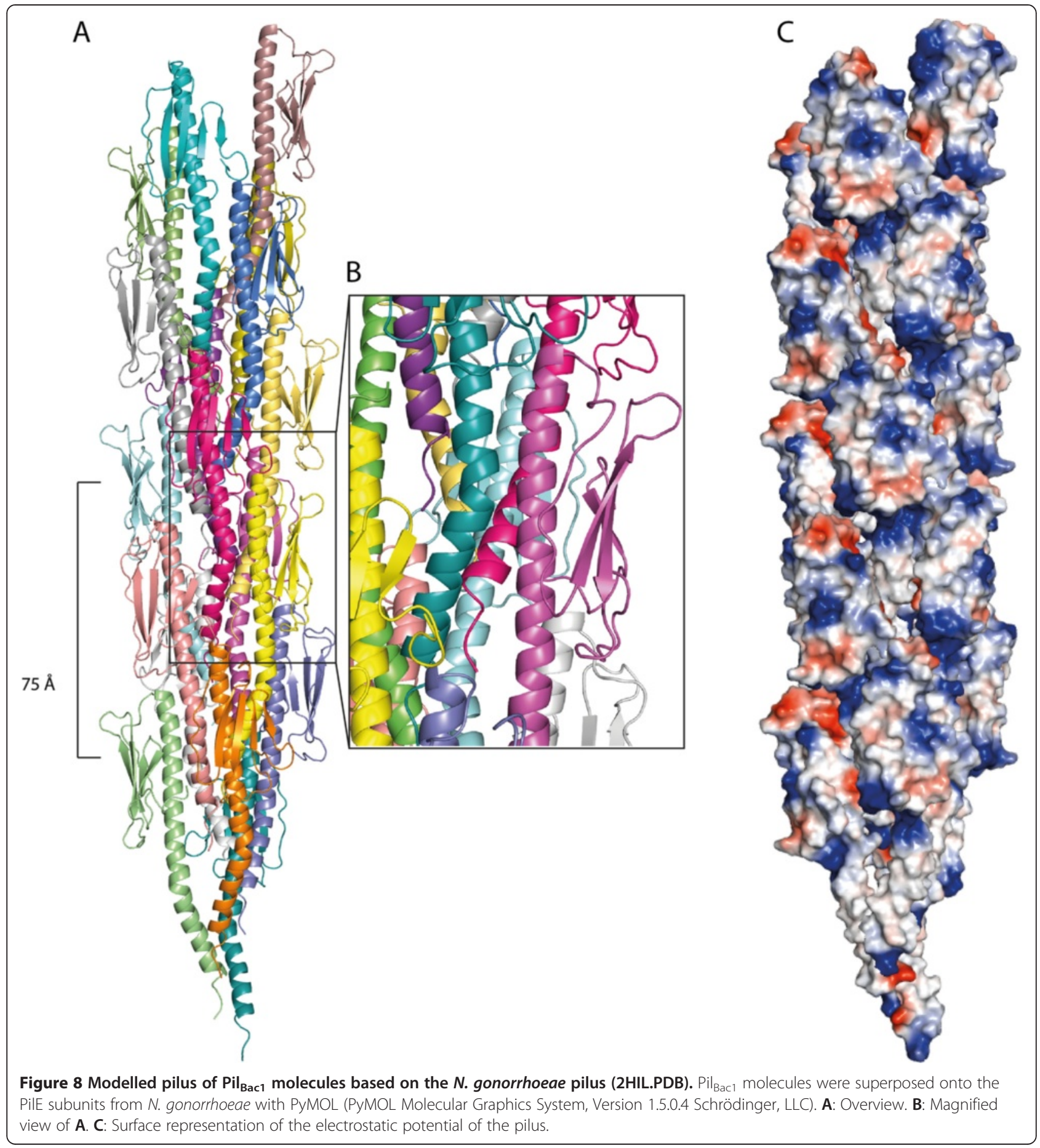

The NMR structure of PilA from G. sulfurreducens showed that the aromatic side chains were indeed closely spaced with a maximum distance of $15 \AA$ [43]; yet, to the best of our knowledge, the maximum distance between aromatic groups that allows for electron transfer has not been defined so far. Similar to G. sulfurreducens, S. oneidensis forms conductive nanowires and, based on the overall similarity between these two organisms including metabolic pathways and the prevalence of multiheme cytochromes, a similar electron transfer mechanism is very likely. $\mathrm{Pil}_{\mathrm{Bac} 1}$ is the type IV pilin which is most closely related to PilA from G. sulfurreducens based on sequence comparisons (Additional file 2: Table S2). The full-length chimeric model of $\mathrm{Pil}_{\mathrm{Bac} 1}$ contained 14 aromatic residues including two 
phenylalanines and one tyrosine in the modelled transmembrane domain. In the modelled pilus of $\mathrm{Pil}_{\mathrm{Bac1}}$ subunits, the aromatic side chains were evenly spaced throughout the whole structure, with some being closer to their neighbors than others (Figure 9A). A long chain of aromatic side chains wound along the modelled filament with two clusters on each subunit in which the aromatics are closely positioned to each other with distances between 4 to $7 \AA$. Yet, these two clusters are separated by a gap of $11 \AA$ which can be defined as the maximum distance between two aromatics in the pilus model. This distance compares well to PilA from Geobacter; however, the arrangement of aromatic side chains in PilE from $N$. gonorrhoeae - which has not been shown to produce conductive nanowires yet - is similar with a maximum distance between individual aromatic side chains of around $13 \AA$ (Additional file 8: Figure S4). This may argue against the hypothesis stating that conductivity is based on a specific alignment of aromatic side chains.

\section{Conclusions}

In this study we described the high-resolution structure of the N-terminally truncated type IV pilin $\mathrm{Pil}_{\text {Bac1 }}$ which exhibits the typical fold of type IV pilins with a long Nterminal $\alpha$-helix packed against 4 antiparallel $\beta$-strands. $\mathrm{Pil}_{\mathrm{Bac1}}$ was crystallized as a parallel dimer with a sodium ion bound to one of the monomers. Small-angle X-Ray scattering studies of the $\mathrm{N}$-terminally truncated $\mathrm{Pil}_{\mathrm{Bac} 1}$ indicated that the protein exists as a monomer in solution, but further characterization of the full-length form and/or membrane bound form will be necessary to clarify the oligomeric state of $\mathrm{Pil}_{\mathrm{Bac} 1}$ in a cellular context. In contrast to most other $\mathrm{T} 4 \mathrm{aP}$ head domains, $\mathrm{Pil}_{\mathrm{Bac} 1}$ displays a straight $\alpha$-helix and a small head domain which leads to a less dense packing mode in a modelled pilus compared to other well-characterized pilins and possibly making room for interaction partners such as multiheme cytochromes.

\section{Methods}

Cloning, expression and purification

The DNA coding for residues 36 to 123 of $\mathrm{Pil}_{\text {Bac } 1}$ from $S$. oneidensis with LIC overhangs at the 5' and 3' ends was amplified by Polymerase Chain Reaction (PCR) using genomic DNA from cell lysates as a template (forward primer: GACGACGACAAGATGGATTACGACATCCCCACTAC

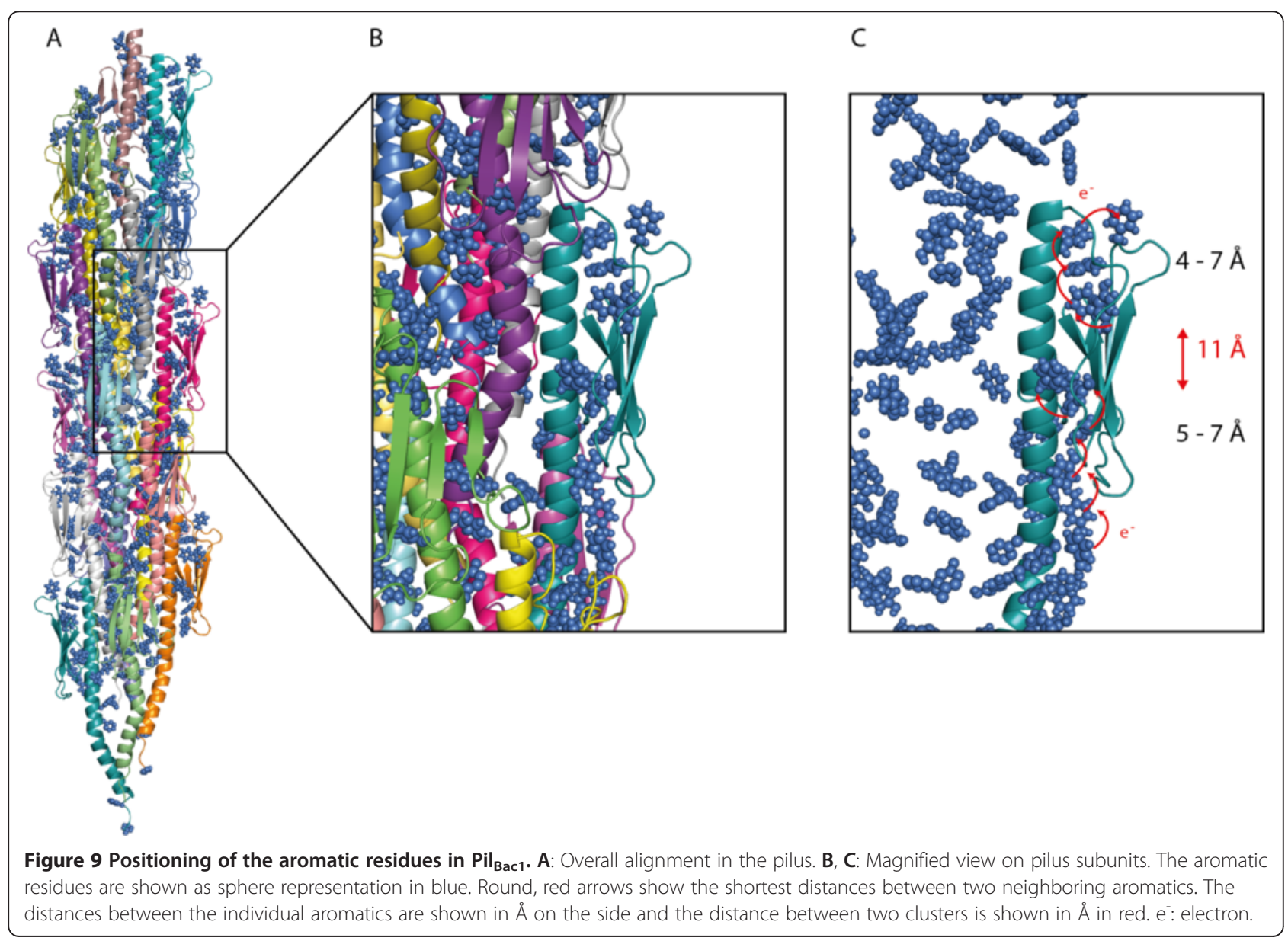


TGAGAATCTTTATTTTCAGGGCAAGCAAGGCAGAC GCTTCGATGCGC; reverse primer: GAGGAGAAGCCC GGTTTAATGGCTCCAACAATTTGTGGCGGGG). The PCR fragment obtained was then inserted into the vector pET-46 Ek/LIC by ligation independent cloning (LIC Kit, Novagen, USA). An N-terminal His tag and an Enterokinase (EK) site are part of pET-46 Ek/LIC vector and a sequence encoding a Tobacco Etch Virus (TEV) protease cleavage site (marked in italics above) was included in the forward primer from the PCR. The correct insert of the plasmid was verified by sequencing and it was transformed into $E$. coli BL 21 DE3 Origami cells (Novagen, USA).

6-12 L of LB medium (containing $100 \mu \mathrm{g} / \mathrm{ml}$ ampicillin and $50 \mu \mathrm{g} / \mathrm{ml}$ kanamycin) were inoculated with $60-120 \mathrm{ml}$ of overnight culture and grown at $37^{\circ} \mathrm{C}$ at $120 \mathrm{rpm}$. When an OD600 between 0.6 and 0.8 was reached, expression was induced by the addition of Isopropyl-thiogalactoside (final concentration of $1 \mathrm{mM}$ ) for 18 hours at $20^{\circ} \mathrm{C}$. Cells were harvested by centrifugation at 8,927.1 $g$ for 20 minutes. The cell pellets were resuspended in $25 \mathrm{ml} \mathrm{LB} /$ liter culture, flash-frozen in liquid nitrogen and stored at $-20^{\circ} \mathrm{C}$ until use.

Cell pellets were resuspended in $3 \mathrm{ml}$ lysis buffer (20 $\mathrm{mM}$ Tris- $\mathrm{HCl} \mathrm{pH} \mathrm{7.5,} 500 \mathrm{mM} \mathrm{KCl,} \mathrm{10 \%} \mathrm{Glycerol)} \mathrm{per}$ gram wet cell pellet and opened by sonication on ice. Unopened cells and cell debris were spun down by centrifugation at approximately $235,000 \mathrm{~g}$ at $4{ }^{\circ} \mathrm{C}$ for $2 \mathrm{~h}$. Imidazole was added to the supernatant to a final concentration of $10 \mathrm{mM}$ and loaded onto a $5 \mathrm{ml}$ nickelchelating column (GE Healthcare, USA) that had been pre-equilibrated in lysis buffer and $10 \mathrm{mM}$ imidazole. After washing with lysis buffer with $10 \mathrm{mM}$ imidazole, the protein was eluted on an ÄKTA Prime with a gradient from $25-500 \mathrm{mM}$ imidazole over 10 column volumes at $1 \mathrm{ml} / \mathrm{min}$ and fractions containing $\mathrm{Pil}_{\mathrm{Bac} 1}$ were pooled. The N-terminal His-tag was cleaved off the protein by the TEV protease during dialysis against $1 \mathrm{l}$ lysis buffer at $4^{\circ} \mathrm{C}$ for $12 \mathrm{~h}$. The protein was then loaded onto a $5 \mathrm{ml}$ nickel-chelating column (GE Healthcare, USA) and the flow-through containing the cleaved protein was collected and concentrated on a 5 molecular weight cutoff concentrator. $\mathrm{Pil}_{\mathrm{Bac} 1}$ was further purified by a size exclusion step on a Superdex 75 10/300 (GE Healthcare, USA) equilibrated in $20 \mathrm{mM}$ Tris- $\mathrm{HCl} \mathrm{pH} 7.5,100 \mathrm{mM}$ $\mathrm{NaCl}$. Finally, Pil $\mathrm{Bac}_{1}$ was concentrated to $15 \mathrm{mg} / \mathrm{ml}$ and stored at $-80^{\circ} \mathrm{C}$.

\section{Synchrotron radiation circular dichroism}

SRCD studies were performed at the CD1 beam line of the ASTRID synchrotron, Aarhus University, Denmark $[88,89]$. Light from the $\mathrm{CD} 1$ beam line passed through an $\mathrm{MgF}$ Rochon polarizer (B-Halle $\mathrm{GmbH}$, Berlin) and alternating left and right circularly polarized light was produced using a photo-elastic modulator (Hinds, USA). The polarized light then passed through the sample and was detected by a photomultiplier tube (9406B, ETL, UK). SRCD spectra were taken from $280 \mathrm{~nm}$ to a minimum wavelength of $190 \mathrm{~nm}$. To investigate the stability of the protein, spectra were recorded with increasing temperature from 7 to $81^{\circ} \mathrm{C}\left(5^{\circ} \mathrm{C}\right.$ per step; 3 measurements at each temperature). After such a temperature scan, the sample was cooled down to $24^{\circ} \mathrm{C}$ and three final spectra were recorded after incubation at $24^{\circ} \mathrm{C}$ for $9 \mathrm{~h}$.

All spectra were recorded at a concentration of $0.66 \mathrm{mg} / \mathrm{ml}$, in $100 \mathrm{mM} \mathrm{NaCl}, 20 \mathrm{mM}$ TRIS pH 7.5. Before and after each temperature scan, a spectrum of the buffer was recorded to check that no changes had occurred during the sample measurement (e.g. damage to the cell, changes in beam). The two buffer spectra were averaged and subtracted from the sample spectra using a spreadsheet operation.

Principal component analysis of the set of $\mathrm{CD}$ spectra recorded over the temperature range 7 to $81^{\circ} \mathrm{C}$ was performed using the Multibase 2013 (http://www.numericaldynamics.com/) add-in for excel to yield the component curves (Figure 2B) and corresponding coefficients for each temperature (Figure 2C). The resulting coefficients were each fitted by a sigmoidal function to find the inflection point and hence the melting temperature for that component.

\section{Thermofluor}

A Thermofluor experiment was performed with $\operatorname{Pil}_{\mathrm{Bac} 1} \Delta \mathrm{N}$ in $100 \mathrm{mM} \mathrm{NaCl}, 20 \mathrm{mM}$ TRIS pH $7.5(25 \mu \mathrm{M})$ and with 10xSYPRO Orange (Sigma Aldrich) using a Light Cycler 480 (Roche) and the option for protein melting dynamics. The temperature was increased from 20 to $85^{\circ} \mathrm{C}$ with $4.4^{\circ} \mathrm{C}$ per $\mathrm{s}$ and the fluorescence was measured with 20 acquisitions per time point. Plotting the fluorescence against the temperature yielded a sigmoidal curve. The inflection point of this curve was approximated as the melting temperature of $\operatorname{Pil}_{\text {Bac1 }} \Delta \mathrm{N}$.

\section{X-Ray crystallography \\ Crystallization, data collection and processing}

$\mathrm{Pil}_{\text {Bac1 }} \Delta \mathrm{N}$ was crystallized at a concentration of $15 \mathrm{mg} / \mathrm{ml}$ in a hanging drop set-up in a 2:1 ratio with the reservoir (26\% PEG 8,000, $0.15 \mathrm{M}\left(\mathrm{NH}_{4}\right)_{2} \mathrm{SO}_{4}$ and $0.1 \mathrm{M}$ CHES $\mathrm{pH} 8.6)$ at $19^{\circ} \mathrm{C}$. Rod shaped crystals appeared after a few days and were stored in liquid nitrogen without the addition of more cryoprotectant.

A high resolution data set was collected from crystals at beamline BL14.2, Bessy II, Berlin, [90] at $0.98 \AA$ with $0.5 \mathrm{~s}$ of exposure time (Table 1). All data were processed and merged with the XDS software [59]. The Wilson B-factor was determined by the program AIMLESS [91]. The Matthews coefficient [92] and the solvent content were 
derived by the program XTRIAGE from the Phenix suite [60]. See also Table 1 for data collection and processing statistics.

\section{Structure determination and analysis}

The S-SAD structure of $\mathrm{Pil}_{\mathrm{Bac}} \Delta \mathrm{N}$ (PDB accession code 4US7) was used as a search model for molecular replacement using the program PHASER [93] from the Phenix suite. The model was refined with Phenix.Refine [60] with the options for xyz coordinates, TLS, individual Bfactors, optimizing X-Ray stereochemical weights and ADP weights with iterative model building in Coot [61]. In the last steps, the model was refined including riding hydrogen atoms. The model was validated with the program MOLPROBITY [94] and deposited in the protein data bank with the accession code 4D40.

The electrostatics for the monomer were calculated using the PDB2PQR (version 1.8) server at http://nbcr222.ucsd.edu/pdb2pqr_1.9.0/ with standard parameters and force field = PARSE. Files from PDB2PQR were used with the APBS [95] plugin in PyMOL 1.7.4 to generate images, coloring a range of $+/-5 \mathrm{kT} / \mathrm{e}$ by potential on the solvent accessible surface. The electrostatics for the pilus model was calculated using the built-in feature of PyMOL.

The structure of $\mathrm{Pil}_{\mathrm{Bac1}} \Delta \mathrm{N}$ was superposed onto PilE from $N$. gonorrhoeae (PDB accession code 2HI2) [34] based on the $C_{\alpha}$ s of the $\alpha$-helix and the first two $\beta$-strands and the first 28 residues of PilE were then added onto $\operatorname{Pil}_{\text {Bac1 }} \Delta \mathrm{N}$ using PyMOL (PyMOL Molecular Graphics System, Version 1.5.0.4 Schrödinger, LLC). Residues 9 (V) and 23 to 28 (AYQDYT) were then mutated into the corresponding residues in $\mathrm{Pil}_{\mathrm{Bac} 1}$ (A; SFNFYL) and the modelled helix was subjected to energy minimization using torsion angle and Ramachandran constraints in COOT [61]. The minimized chimera structure was superposed on the first 28 residues of the subunits in the Neisseria PilE pilus model (PDB accession code 2HIL) [34] in order to generate a $\operatorname{Pil}_{\text {Bac1 }} \Delta \mathrm{N}$ pilus model.

\section{Small-angle X-Ray scattering Data collection}

The data collection parameters are given in Additional file 6: Table S4. Before and after a scattering profile of the protein was recorded, SAXS data of the buffer were collected. The data for the buffer were merged and subtracted from the protein (in buffer) scattering curve to yield the protein scattering curve.

\section{Data processing and model building}

The scattering data were processed with programs from the ATSAS package (PRIMUS [96], DAMMIF [81] DAMAVER [97]). The radius of gyration and the maximum diameter of the protein were calculated with the PRIMUS and GNOM programs. 12 ab initio models consisting of dummy atoms were made with DAMMIF. The models from DAMMIF were evaluated with DAMAVER and for all models, the normalized spatial discrepancy (NSD) deviated no more than two standard variations from the mean value, thus no models were excluded [97]. Envelopes were made based on the DAMMIF model displaying the lowest NSD to the remaining models using the SITUS package and the pdb2vol program using default settings [85]. The X-Ray structure of $\mathrm{Pil}_{\mathrm{Bac} 1} \Delta \mathrm{N}$ was docked into the envelope obtained from pdb2vol using the program SUPCOMB [82] and the model was visualized in UCSF Chimera [83]. To compare the SAXS model to the crystal structure, a theoretical scattering curve was generated based on the crystal structure using CRYSOL [84].

\section{Additional files}

Additional file 1: Table S1. Structures of T4Ps and pseudopilins. "b" indicates a $\beta$-sheet, "a" an a-helix [98-103].

Additional file 2: Table S2. Sequence identities between T4Ps from $S$. oneidensis ( $\mathrm{Pil}_{\mathrm{Bac} 1} \mathrm{So}$, PilESo, PilASo, MshASo, MshBSo, $\mathrm{Pil}_{\mathrm{Bac} 2} \mathrm{So}, \mathrm{Pil}_{\mathrm{Bac} 3} \mathrm{So}$, $\mathrm{Pil}_{\mathrm{Bac} 4} \mathrm{So}$, PillSSo, PilXSo) with PilA from G. sulfurreducens. The alignment was done using the program MUSCLE [53].

Additional file 3: Figure S1. Sequence alignment of T4Ps from $S$. oneidensis (Pil $\mathrm{Bac}_{1} \mathrm{So}, \mathrm{PilESO}$, PilASo, MshASo, MshBSo, $\mathrm{Pil}_{\mathrm{Bac} 2} \mathrm{SO}, \mathrm{Pil}_{\mathrm{Bac} 3} \mathrm{SO}$, $\mathrm{Pil}_{\mathrm{Bac} 4} \mathrm{SO}$, PilVSo, PilXSo) with PilA from G. sulfurreducens. The alignment was done using the program MUSCLE [53].

Additional file 4: Figure S2. Positive density at the interface to the solvent channels. A: Overview over the unit cell. B: Positive density at residues 3 and 5 in chain A. The 2Fo-Fc map was contoured at 1.50, Fo-Fc map at $3 \sigma$.

Additional file 5: Table S3. Identification of homologous proteins to $\mathrm{Pil}_{\mathrm{Bac}} \triangle \mathrm{N}$ by the DALI server [65]. The R.M.S.D. value between the structures obtained from DALI based on $C_{a s}$ is given. Additionally, the number of residues in the structure is given. The three most homologous T4P structures and the most homologous pseudopilin structure are highlighted in bold.

Additional file 6: Table S4. SAXS data collection parameters and data processing statistics. The dry volume was calculated by an online server based on considerations from Harpaz et al. [104]. The molecular mass was determined by Porod volume analysis with the program AUTOPOROD [105].

Additional file 7: Figure S3. SAXS data. A: Original SAXS curves. B: SAXS curve for $16 \mathrm{mg} / \mathrm{ml}$. C: Guinier plot for $16 \mathrm{mg} / \mathrm{ml}$. D: Porod plot for $16 \mathrm{mg} / \mathrm{ml}$. E: Kratky plot for $16 \mathrm{mg} / \mathrm{ml}$. F: Pair-distance distribution plot $\mathrm{p}$ (r). s: momentum transfer, I: scattering intensity.

Additional file 8: Figure S4. Conservation of aromatic amino acids in Pil $_{\text {Bacl }}$ from S. oneidensis (blue), PilA from G. sulfurreducens (yellow) and PilE from N. gonnorhoeae (red). A: Cartoon presentation of all three pilins. B: Cartoon presentation of PilA from G. sulfurreducens and the aromatics in all three pilins shown as sticks.

\section{Abbreviations}

EET: Extracellular Electron Transport; EM: Electron Microscopy; NMR: Nuclear Magnetic Resonance; ORF: Open Reading Frame; PCA: Principle Component Analysis; PISA: Proteins, Interfaces, Structures and Assemblies; SAXS: Small-Angle X-Ray Scattering; SRCD: Synchrotron Radiation Circular Dichroism; S-SAD: Sulfur-Single-wavelength Anomalous Diffraction; T4P: Type IV Pilin.

\section{Competing interests}

The authors declare that they have no competing interests. 


\section{Authors' contributions}

MG and JJU performed the experiments. MG, NCJ and SVH did the SRCD analysis. $M G$ and $A B$ determined the structure. MG and TB wrote the manuscript and all authors commented on it. Project planning and development was carried out by MG under supervision of TB and PN. All authors read and approved the final manuscript.

\section{Acknowledgements}

We would like to thank the Graduate School of Science and Technology, Aarhus University, and the Pumpkin - Centre for membrane pumps in cells and disease for partial funding of the Ph.D. project of M. Gorgel. The work was supported by the advanced research program BIOMEMOS of the European Research Council (to PN) and by the Danish Council for Technological and Production-related Research on the project Micro-cable based bionanoelectronics (supporting TB). We are grateful to Dr. Manfred S. Weiss, Helmholtz Zentrum Berlin, for help with data collection. We thank the staff at MAX-LAB beamline 1911 SAXS for help with data collection. Travel costs to Bessy and MAX-lab were financed by the Biostruct-X project 5624.20.

\section{Author details}

${ }^{1}$ Department of Molecular Biology and Genetics, Aarhus University, Gustav Wieds Vej 10c, Aarhus C 8000, Denmark. ${ }^{2}$ ISA, Department of Physics and Astronomy, Aarhus University, Ny Munkegade 120, building 1525, Aarhus C 8000, Denmark.

\section{Received: 6 January 2015 Accepted: 2 February 2015}

\section{Published online: 27 February 2015}

\section{References}

1. Giltner CL, van Schaik EJ, Audette GF, Kao D, Hodges RS, Hassett DJ, et al. The Pseudomonas aeruginosa type IV pilin receptor binding domain functions as an adhesin for both biotic and abiotic surfaces (vol 59, pg 1083, 2006). Mol Microbiol. 2006;60(3):813-3.

2. Christie PJ, Atmakuri K, Krishnamoorthy V, Jakubowski S, Cascales E. Biogenesis, architecture, and function of bacterial type IV secretion systems. Annu Rev Microbiol. 2005;59:451-85.

3. Giltner $C L$, Nguyen Y, Burrows LL. Type IV pilin proteins: versatile molecular modules. Microbiol Mol Biol R. 2012;76(4):740-72.

4. Cehovin A, Simpson PJ, McDowell MA, Brown DR, Noschese R, Pallett M, et al. Specific DNA recognition mediated by a type IV pilin. Proc Natl Acad Sci U S A. 2013;110(8):3065-70.

5. Melican K, Michea Veloso P, Martin T, Bruneval P, Dumenil G. Adhesion of Neisseria meningitidis to dermal vessels leads to local vascular damage and purpura in a humanized mouse model. Plos Pathog. 2013;9(1):e1003139.

6. Melville S, Craig L. Type IV pili in gram-positive bacteria. Microbiol Mol Biol R. 2013;77(3):323-41.

7. Reguera G, McCarthy KD, Mehta T, Nicoll JS, Tuominen MT, Lovley DR. Extracellular electron transfer via microbial nanowires. Nature. 2005;435(7045):1098-101.

8. Reguera G, Pollina RB, Nicoll JS, Lovley DR. Possible nonconductive role of Geobacter sulfurreducens pilus nanowires in biofilm formation. J Bacteriol. 2007;189(5):2125-7.

9. Gorby YA, Yanina S, McLean JS, Rosso KM, Moyles D, Dohnalkova A, et al. Electrically conductive bacterial nanowires produced by Shewanella oneidensis strain MR-1 and other microorganisms. Proc Natl Acad Sci U S A. 2006;103(30):11358-63.

10. Myers $\mathrm{CR}$, Nealson $\mathrm{KH}$. Bacterial manganese reduction and growth with manganese oxide as the sole electron acceptor. Science. 1988;240(4857):1319-21.

11. Caccavo F, Lonergan DJ, Lovley DR, Davis M, Stolz JF, Mcinerney MJ. Geobacter sulfurreducens Sp-Nov, a hydrogen-oxidizing and acetateoxidizing dissimilatory metal-reducing microorganism. Appl Environ Microb. 1994;60(10):3752-9.

12. Lonergan DJ, Jenter HL, Coates JD, Phillips EJP, Schmidt TM, Lovley DR. Phylogenetic analysis of dissimilatory Fe(III)-reducing bacteria. J Bacteriol. 1996;178(8):2402-8.

13. Bencheikh-Latmani R, Williams SM, Haucke L, Criddle CS, Wu LY, Zhou JZ, et al. Global transcriptional profiling of Shewanella oneidensis MR-1 during Cr(VI) and U(VI) reduction. Appl Environ Microb. 2005;71(11):7453-60.
14. Gregory KB, Lovley DR. Remediation and recovery of uranium from contaminated subsurface environments with electrodes. Environ Sci Technol. 2005;39(22):8943-7.

15. Nealson KH, Scott J. Ecophysiology of the Genus Shewanella. Proc Natl Acad Sci U S A. 2006;6:1133-51.

16. Shi L, Chen BW, Wang ZM, Elias DA, Mayer MU, Gorby YA, et al. Isolation of a high-affinity functional protein complex between OmcA and MtrC: Two outer membrane decaheme c-type cytochromes of Shewanella oneidensis MR-1. J Bacteriol. 2006;188(13):4705-14.

17. Ross DE, Ruebush SS, Brantley SL, Hartshorne RS, Clarke TA, Richardson DJ, et al Characterization of protein-protein interactions involved in iron reduction by Shewanella oneidensis MR-1. Appl Environ Microb. 2007;73(18):5797-808.

18. Mehta T, Coppi MV, Childers SE, Lovley DR. Outer membrane c-type cytochromes required for Fe(III) and Mn(IV) oxide reduction in Geobacter sulfurreducens. Appl Environ Microb. 2005;71(12):8634-41.

19. Nevin KP, Kim BC, Glaven RH, Johnson JP, Woodard TL, Methe BA, et al. Anode biofilm transcriptomics reveals outer surface components essential for high density current production in Geobacter sulfurreducens fuel cells. Plos One. 2009;4(5):e5628.

20. Lies DP, Hernandez ME, Kappler A, Mielke RE, Gralnick JA, Newman DK. Shewanella oneidensis MR-1 uses overlapping pathways for iron reduction at a distance and by direct contact under conditions relevant for biofilms. Appl Environ Microb. 2005;71(8):4414-26.

21. Kotloski NJ, Gralnick JA. Flavin electron shuttles dominate extracellular electron transfer by Shewanella oneidensis. Mbio. 2013;4(1):e00553-00512.

22. Marsili E, Baron DB, Shikhare ID, Coursolle D, Gralnick JA, Bond DR. Shewanella Secretes flavins that mediate extracellular electron transfer. Proc Natl Acad Sci U S A. 2008;105(10):3968-73.

23. Reguera G, Nevin KP, Nicoll JS, Covalla SF, Woodard TL, Lovley DR. Biofilm and nanowire production leads to increased current in Geobacter sulfurreducens fuel cells. Appl Environ Microb. 2006;72(11):7345-8.

24. Lanthier M, Gregory KB, Lovley DR. Growth with high planktonic biomass in Shewanella oneidensis fuel cells. Fems Microbiol Lett. 2008;278(1):29-35.

25. McLean JS, Wanger G, Gorby YA, Wainstein M, McQuaid J, Ishii SI, et al. Quantification of electron transfer rates to a solid phase electron acceptor through the stages of biofilm formation from single cells to multicellular communities. Environ Sci Technol. 2010;44(7):2721-7.

26. Carmona-Martinez AA, Harnisch F, Fitzgerald LA, Biffinger JC, Ringeisen BR, Schroder U. Cyclic voltammetric analysis of the electron transfer of Shewanella oneidensis MR-1 and nanofilament and cytochrome knock-out mutants. Bioelectrochemistry. 2011;81(2):74-80.

27. Malvankar NS, Vargas M, Nevin KP, Franks AE, Leang C, Kim BC, et al. Tunable metallic-like conductivity in microbial nanowire networks. Nat Nanotechnol. 2011;6(9):573-9.

28. Strycharz-Glaven SM, Snider RM, Guiseppi-Elie A, Tender LM. On the electrical conductivity of microbial nanowires and biofilms. Energ Environ Sci. 2011;4(11):4366-79.

29. Bond DR, Strycharz-Glaven SM, Tender LM, Torres Cl. On electron transport through geobacter biofilms. Chemsuschem. 2012;5(6):1099-105.

30. Malvankar NS, Tuominen MT, Lovley DR. Comment on "On electrical conductivity of microbial nanowires and biofilms" by S. M. Strycharz-Glaven, R. M. Snider, A. Guiseppi-Elie and L. M. Tender, Energy Environ. Sci., 2011, 4, 4366. Energ Environ Sci. 2012;5(3):6247-9.

31. Strycharz-Glaven SM, Tender LM. Reply to the 'Comment on "On electrical conductivity of microbial nanowires and biofilms"' by N. S. Malvankar, M. T. Tuominen and D. R. Lovley, Energy Environ. Sci., 2012, 5. Energ Environ Sci. 2012;5(3):6250-5. DOl: 10.1039/c2ee02613a.

32. Craig L, Taylor RK, Pique ME, Adair BD, Arvai AS, Singh M, et al. Type IV pilin structure and assembly: X-ray and EM analyses of Vibrio cholerae toxin-coregulated pilus and Pseudomonas aeruginosa PAK pilin. Mol Cell. 2003;11(5):1139-50.

33. Craig $L$, Pique ME, Tainer JA. Type IV pilus structure and bacterial pathogenicity. Nat Rev Microbiol. 2004;2(5):363-78.

34. Craig L, Volkmann N, Arvai AS, Pique ME, Yeager M, Egelman EH, et al. Type IV pilus structure by cryo-electron microscopy and crystallography: implications for pilus assembly and functions. Mol Cell. 2006;23(5):651-62.

35. Arts J, van Boxtel R, Filloux A, Tommassen J, Koster M. Export of the pseudopilin XcpT of the Pseudomonas aeruginosa type II secretion system via the signal recognition particle-Sec pathway. J Bacteriol. 2007;189(5):2069-76.

36. Nunn DN, Lory S. Product of the pseudomonas-aeruginosa gene pilD is a prepilin leader peptidase. Proc Natl Acad Sci U S A. 1991;88(8):3281-5. 
37. Strom MS, Lory S. Amino-acid substitutions in pilin of pseudomonasaeruginosa - effect on leader peptide cleavage, amino-terminal methylation, and pilus assembly. J Biol Chem. 1991;266(3):1656-64.

38. Nunn D, Bergman S, Lory S. Products of 3 accessory genes, pilB, pilC, and pilD, Are required for biogenesis of pseudomonas-aeruginosa pili. J Bacteriol. 1990;172(6):2911-9.

39. Chiang P, Habash M, Burrows LL. Disparate subcellular localization patterns of Pseudomonas aeruginosa type IV pilus ATPases involved in twitching motility. J Bacteriol. 2005;187(3):829-39.

40. Chiang P, Sampaleanu LM, Ayers M, Pahuta M, Howel PL, Burrows LL. Functional role of conserved residues in the characteristic secretion NTPase motifs of the Pseudomonas aeruginosa type IV pilus motor proteins PilB, PilT and PilU. Microbiol-Sgm. 2008;154:114-26.

41. Collins RF, Frye SA, Balasingham S, Ford RC, Tonjum T, Derrick JP. Interaction with type IV pili induces structural changes in the bacterial outer membrane secretin PilQ. J Biol Chem. 2005;280(19):18923-30.

42. Wolfgang M, van Putten JPM, Hayes SF, Dorward D, Koomey M. Components and dynamics of fiber formation define a ubiquitous biogenesis pathway for bacterial pili. Embo J. 2000;19(23):6408-18.

43. Reardon PN, Mueller KT. Structure of the type IVa major pilin from the electrically conductive bacterial nanowires of geobacter sulfurreducens. J Biol Chem. 2013;288(41):29260-6.

44. Nguyen Y, Jackson SG, Aidoo F, Junop M, Burrows LL. Structural characterization of novel pseudomonas aeruginosa type IV pilins. J Mol Biol. 2010;395(3):491-503.

45. Nunn D. Bacterial type II protein export and pilus biogenesis: more than just homologies? Trends Cell Biol. 1999;9(10):402-8

46. Durand E, Bernadac A, Ball G, Lazdunski A, Sturgis JN, Filloux A. Type II protein secretion in Pseudomonas aeruginosa: the pseudopilus is a multifibrillar and adhesive structure. J Bacteriol. 2003;185(9):2749-58.

47. Sandkvist M. Biology of type II secretion. Mol Microbiol. 2001;40(2):271-83.

48. Campos M, Cisneros DA, Nivaskumar M, Francetic O. The type II secretion system - a dynamic fiber assembly nanomachine. Res Microbiol. 2013;164(6):545-55.

49. Sandkvist M. Type II secretion and pathogenesis. Infect Immun. 2001;69(6):3523-35.

50. Parge HE, Forest KT, Hickey MJ, Christensen DA, Getzoff ED, Tainer JA. Structure of the fiber-forming protein pilin at 2.6-angstrom resolution. Nature. 1995;378(6552):32-8.

51. Kohler R, Schafer K, Muller S, Vignon G, Diederichs K, Philippsen A, et al. Structure and assembly of the pseudopilin PulG. Mol Microbiol. 2004;54(3):647-64.

52. Yanez ME, Korotkov KV, Abendroth J, Hol WGJ. The crystal structure of a binary complex of two pseudopilins: Epsl and EpsJ from the type 2 secretion system of vibrio vulnificus. J Mol Biol. 2008;375(2):471-86.

53. Edgar RC. MUSCLE: multiple sequence alignment with high accuracy and high throughput. Nucleic Acids Res. 2004;32(5):1792-7.

54. Kuhn J, Briegel A, Morschel E, Kahnt J, Leser K, Wick S, et al. Bactofilins, a ubiquitous class of cytoskeletal proteins mediating polar localization of a cell wall synthase in Caulobacter crescentus. Embo J. 2010;29(2):327-39.

55. Koch MK, McHugh CA, Hoiczyk E. BacM, an N-terminally processed bactofilin of Myxococcus xanthus, is crucial for proper cell shape. Mol Microbiol. 2011;80(4):1031-51.

56. Bulyha I, Lindow S, Lin L, Bolte K, Wuichet K, Kahnt J, et al. Two small GTPases Act in concert with the bactofilin cytoskeleton to regulate dynamic bacterial cell polarity. Dev Cell. 2013;25(2):119-31.

57. Dupeux F, Rower M, Seroul G, Blot D, Marquez JA. A thermal stability assay can help to estimate the crystallization likelihood of biological samples. Acta Crystallogr D. 2011;67:915-9.

58. Karplus PA, Diederichs K. Linking crystallographic model and data quality. Science. 2012;336(6084):1030-3.

59. Kabsch W. Xds. Acta Crystallogr D. 2010;66:125-32.

60. Afonine PV, Grosse-Kunstleve RW, Echols N, Headd JJ, Moriarty NW, Mustyakimov M, et al. Towards automated crystallographic structure refinement with phenix.refine. Acta Crystallogr D. 2012;68:352-67.

61. Emsley P, Cowtan K. Coot: model-building tools for molecular graphics. Acta Crystallogr D. 2004;60:2126-32.

62. Weiss MS. Global indicators of X-ray data quality. J Appl Crystallogr. 2001;34:130-5.

63. Leang C, Qian XL, Mester T, Lovley DR. Alignment of the c-type cytochrome OmcS along pili of geobacter sulfurreducens. Appl Environ Microb. 2010;76(12):4080-4.
64. Karuppiah V, Collins RF, Thistlethwaite A, Gao Y, Derrick JP. Structure and assembly of an inner membrane platform for initiation of type IV pilus biogenesis. Proc Natl Acad Sci U S A. 2013;110(48):E4638-47.

65. Holm L, Rosenstrom P. Dali server: conservation mapping in 3D. Nucleic Acids Res. 2010;38:W545-9.

66. Helaine $\mathrm{S}$, Dyer DH, Nassif X, Pelicic V, Forest KT. 3D structure/function analysis of PilX reveals how minor pilins can modulate the virulence properties of type IV pili. Proc Natl Acad Sci U S A. 2007;104(40):15888-93.

67. Dunlop KV, Irvin RT, Hazes B. Pros and cons of cryocrystallography: should we also collect a room-temperature data set? Acta Crystallogr D. 2005;61:80-7.

68. Korotkov KV, Gray MD, Kreger A, Turley S, Sandkvist M, Hol WGJ. Calcium is essential for the major pseudopilin in the type 2 secretion system. J Biol Chem. 2009;284(38):25466-70.

69. Holmes DE, Chaudhuri SK, Nevin KP, Mehta T, Methe BA, Liu A, et al. Microarray and genetic analysis of electron transfer to electrodes in Geobacter sulfurreducens. Environ Microbiol. 2006;8(10):1805-15.

70. Richter LV, Sandler SJ, Weis RM. Two isoforms of Geobacter sulfurreducens PilA have distinct roles in pilus biogenesis, cytochrome localization, extracellular electron transfer, and biofilm formation. J Bacteriol. 2012;194(10):2551-63.

71. Watts TH, Worobec EA, Paranchych W. Identification of pilin pools in the membranes of pseudomonas-aeruginosa. J Bacteriol. 1982;152(2):687-91.

72. Pugsley AP. Multimers of the precursor of a type IV pilin-like component of the general secretory pathway are unrelated to pili. Mol Microbiol. 1996;20(6):1235-45.

73. Petrov A, Lombardo S, Audette GF. Fibril-mediated oligomerization of pilin-derived protein nanotubes. J Nanobiotechnology. 2013;11:24.

74. Audette GF, Irvin RT, Hazes B. Crystallographic analysis of the Pseudomonas aeruginosa strain K122-4 monomeric pilin reveals a conserved receptorbinding architecture. Biochemistry-Us. 2004;43(36):11427-35.

75. Yanez ME, Korotkov KV, Abendroth J, Hol WGJ. Structure of the minor pseudopilin EpsH from the type 2 secretion system of Vibrio cholerae. J Mol Biol. 2008;377(1):91-103.

76. Lim MS, Ng D, Zong ZS, Arvai AS, Taylor RK, Tainer JA, et al. Vibrio cholerae El Tor TcpA crystal structure and mechanism for pilus-mediated microcolony formation. Mol Microbiol. 2010;77(3):755-70.

77. Hartung S, Arvai AS, Wood T, Kolappan S, Shin DS, Craig L, et al. Ultrahigh Resolution and Full-length Pilin Structures with Insights for Filament Assembly, Pathogenic Functions, and Vaccine Potential. J Biol Chem. 2011;286(51):44254-65.

78. Kolappan S, Roos J, Yuen ASW, Pierce OM, Craig L. Structural characterization of CFA/III and Longus type IVb Pili from Enterotoxigenic Escherichia Coli. J Bacteriol. 2012;194(10):2725-35.

79. Lomize MA, Pogozheva ID, Joo H, Mosberg HI, Lomize AL. OPM database and PPM web server: resources for positioning of proteins in membranes. Nucleic Acids Res. 2012;40(Database issue):D370-6.

80. Forest KT, Dunham SA, Koomey M, Tainer JA. Crystallographic structure reveals phosphorylated pilin from Neisseria: phosphoserine sites modify type IV pilus surface chemistry and fibre morphology. Mol Microbiol. 1999;31(3):743-52.

81. Franke D, Svergun DI. DAMMIF, a program for rapid ab-initio shape determination in small-angle scattering. J Appl Crystallogr. 2009;42:342-6.

82. Kozin MB, Svergun DI. Automated matching of high- and low-resolution structural models. J Appl Crystallogr. 2001;34:33-41.

83. Pettersen EF, Goddard TD, Huang CC, Couch GS, Greenblatt DM, Meng EC, et al. UCSF Chimera-a visualization system for exploratory research and analysis. J Comput Chem. 2004;25(13):1605-12.

84. Svergun D, Barberato C, Koch MHJ. CRYSOL - a program to evaluate x-ray solution scattering of biological macromolecules from atomic coordinates. J Appl Crystallogr. 1995;28:768-73.

85. Wriggers W. Using Situs for the integration of multi-resolution structures. Biophys Rev. 2010;2(1):21-7.

86. Krissinel E, Henrick K. Inference of macromolecular assemblies from crystalline state. J Mol Biol. 2007;372(3):774-97.

87. Harvey H, Habash M, Aidoo F, Burrows LL. Single-residue changes in the C-terminal disulfide-bonded loop of the pseudomonas aeruginosa type IV Pilin influence pilus assembly and twitching motility. J Bacteriol. 2009;191(21):6513-24.

88. Miles AJ, Hoffmann SV, Tao Y, Janes RW, Wallace BA. Synchrotron radiation circular dichroism (SRCD) spectroscopy: New beamlines and new applications in biology. Spectrosc-Int J. 2007;21(5-6):245-55.

89. Miles AJ, Janes RW, Brown A, Clarke DT, Sutherland JC, Tao Y, et al. Light flux density threshold at which protein denaturation is induced by 
synchrotron radiation circular dichroism beamlines. J Synchrotron Radiat. 2008;15:420-2

90. Mueller U, Darowski N, Fuchs MR, Forster R, Hellmig M, Paithankar KS, et al. Facilities for macromolecular crystallography at the Helmholtz-Zentrum Berlin. J Synchrotron Radiat. 2012;19:442-9.

91. Evans PR, Murshudov GN. How good are my data and what is the resolution? Acta Crystallogr D. 2013;69:1204-14

92. Matthews BW. Solvent content of protein crystals. J Mol Biol. 1968;33(2):491.

93. Mccoy AJ, Grosse-Kunstleve RW, Adams PD, Winn MD, Storoni LC, Read RJ. Phaser crystallographic software. J Appl Crystallogr. 2007;40:658-74.

94. Chen VB, Arendall WB, Headd JJ, Keedy DA, Immormino RM, Kapral GJ, et al. MolProbity: all-atom structure validation for macromolecular crystallography. Acta Crystallogr D. 2010;66:12-21.

95. Baker NA, Sept D, Joseph S, Holst MJ, McCammon JA. Electrostatics of nanosystems: application to microtubules and the ribosome. Proc Natl Acad Sci U S A. 2001;98(18):10037-41.

96. Konarev PV, Volkov W, Sokolova AV, Koch MHJ, Svergun DI. PRIMUS: a Windows PC-based system for small-angle scattering data analysis. J Appl Crystallogr. 2003;36:1277-82.

97. Volkov W, Svergun DI. Uniqueness of ab initio shape determination in small-angle scattering. J Appl Crystallogr. 2003;36:860-4.

98. Hazes B, Sastry PA, Hayakawa K, Read RJ, Irvin RT. Crystal structure of Pseudomonas aeruginosa PAK pilin suggests a main-chain-dominated mode of receptor binding. J Mol Biol. 2000;299(4):1005-17.

99. Balakrishna AM, Saxena AM, Mok HY, Swaminathan K. Structural basis of typhoid: Salmonella typhi type IVb pilin (PilS) and cystic fibrosis transmembrane conductance regulator interaction. Proteins. 2009;77(2):253-61.

100. Helaine S, Carbonnelle E, Prouvensier L, Beretti JL, Nassif X, Pelicic V. PilX, a pilus-associated protein essential for bacterial aggregation, is a key to pilus-facilitated attachment of Neisseria meningitidis to human cells. Mol Microbiol. 2005;55(1):65-77.

101. Alphonse S, Durand E, Douzi B, Waegele B, Darbon H, Filloux A, et al. Structure of the Pseudomonas aeruginosa XcpT pseudopilin, a major component of the type II secretion system. J Struct Biol. 2010;169(1):75-80

102. Franz LP, Douzi B, Durand E, Dyer DH, Voulhoux R, Forest KT. Structure of the minor pseudopilin XcpW from the Pseudomonas aeruginosa type II secretion system. Acta Crystallogr D. 2011:67:124-30.

103. Korotkov KV, Hol WG. Structure of the GspK-Gspl-GspJ complex from the enterotoxigenic Escherichia coli type 2 secretion system. Nat Struct Mol Biol. 2008;15(5):462-8

104. Harpaz Y, Gerstein M, Chothia C. Volume changes on protein folding. Structure 1994:2(7):641-9.

105. Petoukhov MV, Konarev PV, Kikhney AG, Svergun DI. ATSAS 2.1 - towards automated and web-supported small-angle scattering data analysis. J Appl Crystallogr. 2007;40:\$223-8.

\section{Submit your next manuscript to BioMed Central and take full advantage of:}

- Convenient online submission

- Thorough peer review

- No space constraints or color figure charges

- Immediate publication on acceptance

- Inclusion in PubMed, CAS, Scopus and Google Scholar

- Research which is freely available for redistribution

Submit your manuscript at www.biomedcentral.com/submit 